
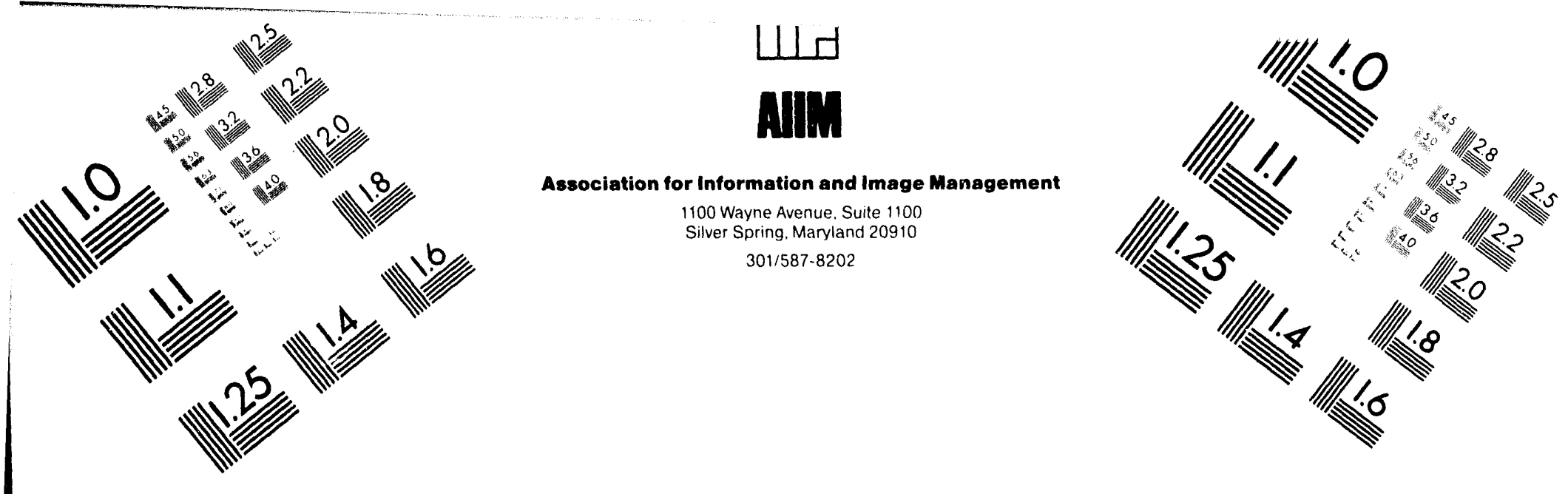

\title{
Centimeter
}

$\begin{array}{llllllllllllllll}1 & 2 & 3 & 4 & 5 & 6 & 7 & 8 & 9 & 10 & 11 & 12 & 13 & 14 & 15 & \mathrm{~mm}\end{array}$

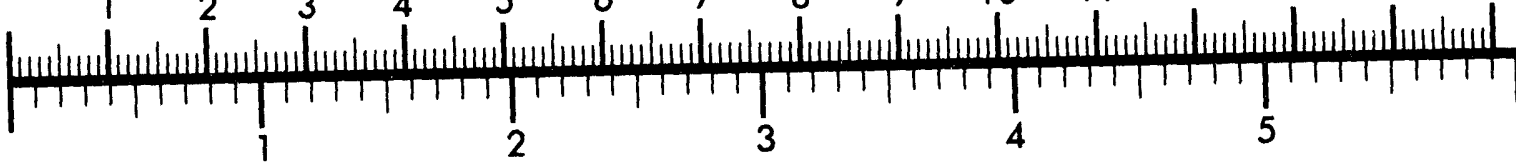
Inches
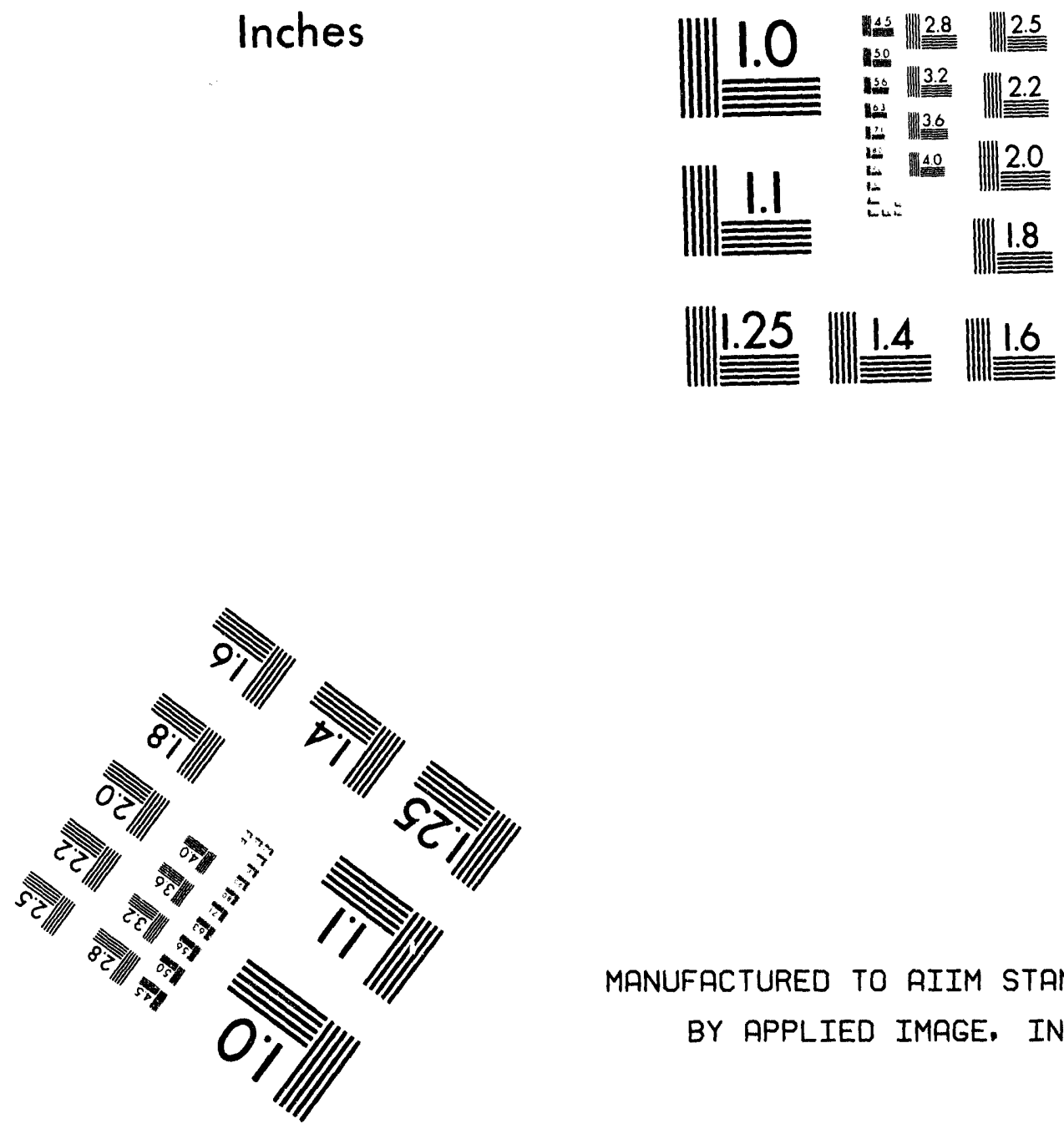

MANUFACTURED TO AIIM STANDARDS BY APPLIED IMAGE. INC.

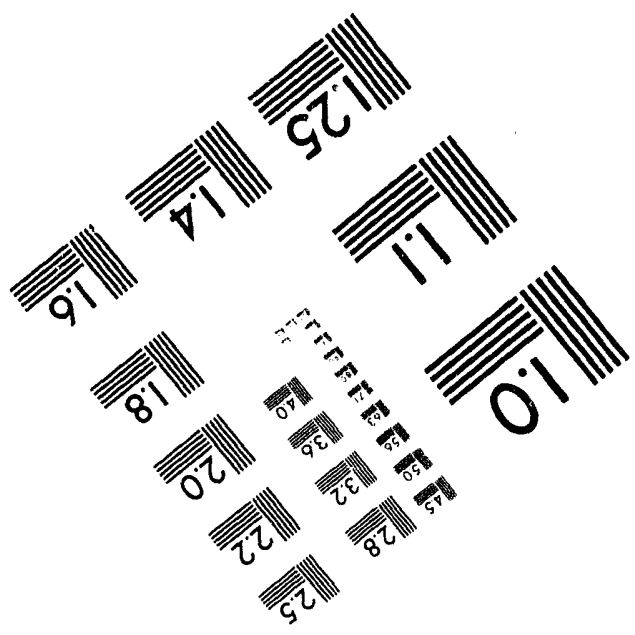



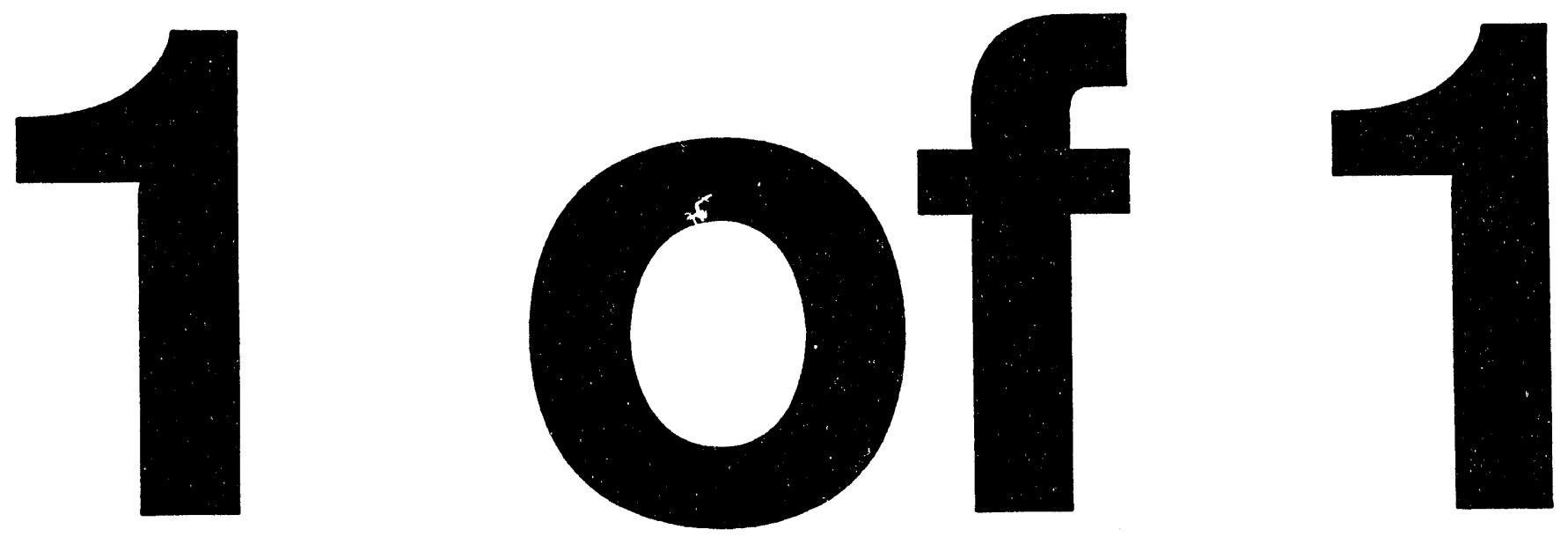
NRRI 94-12

\section{INTEGRATED RESOURCE PLANNING FOR LOCAL GAS DISTRIBUTION COMPANIES: A CRITICAL REVIEW OF REGULATORY POLICY ISSUES}

Mohammad Harunuzzaman, Ph.D.

Research Specialist

Mufakhkharul Islam

Graduate Research Associate

August 1994

This report was prepared by The National Regulatory Research Institute (NRRI) with funding provided by participating member commissions of the National Association of Regulatory Utility Commissioners (NARUC). The views and opinions of the authors do not necessarily state or reflect the views, opinions, or policies of the NRRI, the NARUC, or NARUC member commissions.

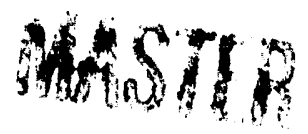




\section{EXECUTIVE SUMMARY}

Public utility commissions (PUCs) are increasingly adopting, or considering the adoption of, integrated resource planning (IRP) for local gas distribution companies (LDCs). The Energy Policy Act of 1992 (EPAct) requires PUCs to consider IRP for gas LDCs. This study has two major objectives: (1) help PUCs develop appropriate regulatory approaches with regard to IRP for gas LDCs; and (2) help PUCs respond to the EPAct directive.

IRP requires a regulated utility to give equal consideration to both supply side and demand-side management (DSM) options in planning a resource mix. IRP has been extensively used as a policy tool to regulate electric utilities; it is a relatively new regulatory approach for gas LDCs. The rapidly developing competition in the energy industry warrants a reexamination of underlying issues and policy goals of IRP. Some of these issues include the nexus between competition and the participatory approach germane to the IRP process, the traditional regulatory issues of cost minimization and ratepayer equity, and the effectiveness of PUC regulation to achieve IRP goals of energy efficiency and environmental protection.

The study finds that it is appropriate for PUCs to pursue energy efficiency within the traditional regulatory framework of minimizing private costs of energy production and delivery. The study concludes that PUCs should play a limited role in addressing environmental externalities.

The study finds that in promoting energy efficiency, PUCs should pursue policies that are incentive-based, procompetitive, and sensitive to rate impacts. The study evaluates a number of traditional ratemaking mechanisms, in addition to nontraditional mechanisms, on the basis of cost minimization, energy efficiency, competitiveness, and other criteria. The mechanisms evaluated include direct recovery of DSM expenses, lost revenue adjustments for DSM options, revenue decoupling mechanisms, sharing of DSM cost savings, performance-based rate of return for DSM, provision of DSM as a separate service, deregulation of DSM service, price caps, ar.j deregulation of the noncore gas 
market. The study concludes with general recommendations for regulatory approaches and ratemaking mechanisms that PUCs may wish to consider in advancing IRP objectives. 


\section{TABLE OF CONTENTS}

FOREWORD $\ldots \ldots \ldots \ldots \ldots \ldots \ldots \ldots \ldots \ldots \ldots \ldots$ vii

ACKNOWLEDGEMENTS $\ldots \ldots \ldots \ldots \ldots \ldots \ldots \ldots \ldots \ldots \ldots$

\section{CHAPTER}

1 Introduction $\ldots \ldots \ldots \ldots \ldots \ldots \ldots \ldots \ldots \ldots \ldots \ldots \ldots$

The Emergence of IRP $\ldots \ldots \ldots \ldots \ldots \ldots \ldots \ldots \ldots \ldots$

Overview of the IRP Process $\ldots \ldots \ldots \ldots \ldots \ldots \ldots$

Study Objectives ...................... 6

2 IRP for the LDC: A Synopsis of Current and

Emerging Practices ..................... 9

Planning and Implementation of an IRP . . . . . . . . .

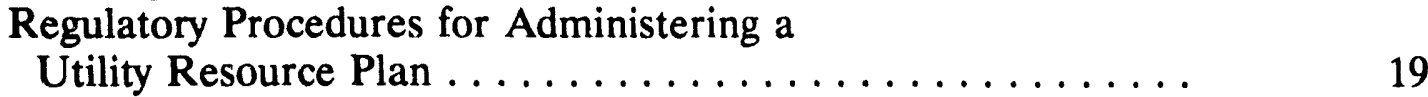

Ratemaking Approaches Used to Promote IRP . . . . . . . . 19

3 IRP for the LDC: An Examination of Issues . . . . . . . . . 27

Generic Issues . . . . . . . . . . . . . . . . . . .

An Examination of IRP Issues Specific to the LDC .......

4 Conclusions and Recommendations $\ldots \ldots \ldots \ldots \ldots$

Summary of Observations ..................

Developing a Policy Framework .................. 54

Developing Regulatory Approaches to Pursue IRP in the New Competitive Environment:

Some Recommendations . . . . . . . . . . . . 



\section{FOREWORD}

Integrated resource planning, which has found considerable acceptance as applied to the electric sector, is increasingly talked about for local natural gas distribution companies. The present study examines the role of IRP for LDCs and provides some insight into appropriate policies that might be considered by state utility regulators in pursuing particular goals.

Douglas N. Jones

Director

Columbus, Ohio

September 1, 1994 


\section{ACKNOWLEDGEMENTS}

The authors wish to thank the reviewers of this report for their comments and suggestions: Janice A. Beecher, Kenneth W. Costello, Dorman Davis, Michel L. Hiser, and Douglas N. Jones. The authors also would like to thank Francine Sevel for her editing of an earlier draft and Marilyn Reiss for her typing and preparation of the final draft. The authors, of course, are responsible for any remaining errors. 


\section{CHAPTER 1}

\section{INTRODUCTION}

Public utility commissions (PUCs) increasingly are adopting, or considering the adoption of, integrated resource planning (IRP) as an oversight approach for regulating local gas distribution companies (LDCs). ${ }^{1}$ This development mirrors a similar development in regulation by electric utilities in the preceding decade. PUCs are confronted, as they continue to incorporate IRP in their regulatory policymaking for LDCs, with a number of issues that require careful examination. Some of these issues date back to the earliest applications of IRP, while others follow from the extensive experience of electric utilities with the IRP process. Last but not least, a number of issues arise from inherent differences between the gas and electric sectors of the energy industry, particularly differences in evolving market structures. This report examines these issues to inform PUCs of the choices of regulatory options available in pursuing IRP objectives.

\section{The Emergence of IRP}

IRP emerged as an oversight approach and an evaluative tool for public utility regulators in the early 1980 s. The emergence of the IRP approach to utility planning was a response to a number of events that occurred in the energy sector, primarily in the electric utility sector. The events accompanied, and reflected, what later became known as the "energy crisis."

Prior to 1970, both real costs and real prices of energy were declining, demand for energy was relatively high and growing, and regulatory oversight exercised by PUCs was

1 Currently, IRP is mandated for LDCs in the District of Columbia and eleven other states. Gas conservation is mandated in five states, LDCs have filed gas demand-side management programs in sixteen states and gas IRP dockets have been opened in eleven states. See Gas Research Institute, Gas IRP Review (January/February 1994). 
characterized by infrequent regulatory hearings and rare instances of cost disallowances. Beginning in the early 1970s, stagflation in the U.S. economy, exacerbated by the Arab oil embargo, led to a number of difficulties for the energy industry. In the electric sector, power-plant construction costs and fuel prices began to rise rapidly while demand growth started to fall significantly below previous forecasts. In the gas sector, the incipient energy crisis accompanied by preexisting 1 'ce controls led to severe gas shortages.

These developments introduced an upward pressure on utility costs and rates that led to greater political pressure on PUCs to exercise closer oversight of utility operations. PUCs generally began to increase the level of scrutiny of utility investments and expenses during rate hearings, which became more frequent, and often awarded large cost disallowances.

The increasing energy costs and shortages also led to a heightened awareness of the consequences of wasteful energy consumption. Two major consequences that were identified included a weakening of national security because of the political leverage held by oil-exporting countries over the United States and other allied nations; and an adverse effect on environmental quality. As a response, a movement emerged that called for greater energy conservation and expanded use of less-polluting sources of energy. PUCs, most of which were already increasing the level of scrutiny of utility operations, chose to become one of the vehicles for pursuing the twin, and related, objectives of energy conservation and environmental protection. The new paradigm, used as both a policy approach and an evaluative tool, that emerged was initially named "least-cost planning" (LCP) or "least-cost utility planning" (LCUP). Since its inception, it has increasingly guided PUC regulation of electric utilities. The PUCs that adopted the LCP approach generally required or otherwise encouraged utilities to give equal consideration of both supply side and demand-side options. The approach also accounts for both the private and the social costs of the energy delivery process. The recognition that the approach seeks to achieve a multiplicity of objectives (which cannot be reduced to a precisely measurable single-cost criterion) and the need for a wider participatory framework (to incorporate social costs) led to a renaming of the new paradigm as "IRP." The IRP 
paradigm stands for both resource integration (to be developed and deployed by the utility) and institutional integration (to be coordinated by the PUC).

\section{Overview of the IRP Process}

The IRP process can be viewed from two perspectives. From the PUC perspective, the process has two basic elements: a set of administrative procedures and ratemaking mechanisms. From the utility perspective, the IRP process can be viewed in terms of stages of implementation.

For a majority of state PUCs, the administrative procedures and ratemaking mechanisms for electric utilities are either fully developed or in advanced stages of development. Such procedures and mechanisms are in early stages of development for LDCs. The procedures used to administer a utility IRP generally require a utility to file a resource plan that includes both supply side and demand-side options, accompanied by an analysis of costs and rate impacts. A PUC may review the filing, allow intervenors to respond to the filing, and issue a ruling or decision. PUCs vary on the form of the review (for example, as part of a rate hearing or a separate review procedure), and the degree of approval implied by the successful completion of the review process (for example, a successful review may or may not constitute a preapproval of the plan or individual parts of the plan). The ratemaking mechanisms generally attempt to allow recovery of investments and expenses of various options, recovery of revenues caused by lost sales due to successful implementation of demand-side management (DSM) options ${ }^{2}$

${ }^{2}$ DSM options include all load-management and energy-conservation options to modify both the total energy consumption and the load profiles of customers. A utility may employ direct load control, pricing, and customer credit and rebate programs to modify customer loads. DSM objectives include peak clipping, peak-load shifting, valley filling, seasonal load reduction, load building, and conservation. For a more detailed explanation, see National Association of Regulatory Utility Commissioners (NARUC), Primer on Gas Integrated Resource Planning (Washington, D.C.: NARUC, December 1993), 151-52. 
or otherwise make supply side and DSM options equally profitable, offer additional financial incentives for successful DSM options, and promote overall cost minimization.

From the utility perspective, the IRP process consists of four distinct stages. In the first stage, the utility develops a resource plan that embodies utility objectives such as minimizing resource costs, maximizing profits, ensuring cost recovery and favorable regulatory treatment, meeting reliability targets, treating uncertainties and risks, and meeting customer needs. The second stage involves submitting the plan for regulatory review (or approval). The review may lead to some modification of the resource plan as a result of intervenor responses and the final PUC ruling. ${ }^{3}$ The third stage consists of implementing the plan. At this stage, the performance of the plan may be closcly monitored. The last stage of the plan consists of developing data, information, and insights to be used in developing a future IRP.

\section{The Rationale of IRP: the Need for Reexamination}

The IRP process, as generally understood and practiced, requires the PUC to direct or otherwise encourage utilities to design their resource plans to promote the basic IRP objectives: efficiency in production and consumption of energy. The underlying objective is to minimize both the private and the social costs of energy production and consumption. The PUC may be considered well-suited to pursue these goals, at least for the electric power industry, because of the authority it exercises over the planning, production, transmission, distribution, and pricing of energy services provided by investor-owned utilities. The rationale of IRP is premised on the view that traditional economic regulation generally provides poor incentives for minimization of private costs (to the utility and consequently to the ratepayers), and that traditional regulation fails to capture, and regulated utilities fail to incorporate, the social costs of energy services.

3 During the first stage there may be PUC and intervenor participation in development of the plan. 
The general "cost-plus" nature of the regulatory arrangement, the rate-of-return (ROR) constraint that regulates utility profits, and the positive relationship between profits and consumption are cited often as some of the reasons for utility behaviors that act as barriers to least-cost production and consumption of energy services. Therefore, it can be argued that PUCs should incorporate IRP objectives into their regulatory practices and oversight mechanisms, and to induce least-cost and socially-efficient resource choices. $^{4}$

A general consensus appears to exist on the desirability of pursuing IRP objectives. There is sharp disagreement, however, on using the regulatory process as an appropriate public intervention vehicle and the ratemaking process as an effective policy instrument for achieving IRP objectives. Some of the opposing arguments can be formulated in terms of: the inaccuracy of characterizing economic regulation as a pure cost-plus arrarigement; ${ }^{5}$ the limitations of competence, informational resources, and jurisdiction of the PUC for inducing "socially-efficient" and "least-cost" resource choices; the apparent incompatibility of the participatory and interventionist approaches germane to the IRP process and the increasing competition in the energy services sector; and the effectiveness of the proposed regulatory schemes to achieve IRP objectives. ${ }^{6}$ As discussed later, the opposing arguments appear to apply more strongly to the gas sector

4 For a general discussion of economic inefficiencies caused by traditional ROR regulation, see Roger Sherman, The Regulation of Monopoly (New York: Cambridge University Press, 1989), 197-200. For a discussion of how the relationship between utility sales and revenues affect utility profits, see David Moskovitz, Cheryl Harrington, and Tom Austin, "Weighing Decoupling vs. Lost Revenues: Regulatory Considerations," The Electricity Journal 5, no. 9 (November 1992): 58-63.

5 Traditional regulation uses retrospective reviews to guard against imprudent and inefficient management. Although a retrospective review may not completely eliminate inefficiencies in utility operations, this regulatory practice does, to some extent, counter the "cost-plus" character of the regulatory arrangement.

6 For a critique of IRP, see Alfred E. Kahn, "An Economically Rational Approach to Least-Cost Planning," The Electricity Jourmal 4, no. 5 (June 1991): 11-20. 
than the electric sector because of differences in industry structure (the gas sector is currently more competitive), production, supply and end-use characteristics, and the magnitude of costs (much smaller for gas) avoided by making alternative resource choices. $^{7}$

The foregoing discussion suggests that a careful reexamination of the IRP approach and related regulatory mechanisms is now warranted. Such a reexamination may generate analytical approaches that can be used to evaluate alternative regulatory schemes. Finally, such a reexamination may help develop new regulatory schemes to better achieve IRP objectives.

\section{Study Objectives}

As discussed, a host of interrelated issues and arguments should be carefully examined by a PUC to decide what form of regulatory guidance and oversight of the LDC ought to be practiced to achieve IRP objectives. This study examines the generic issues embedded in the IRP paradigm, the role of the PUC as an effective public oversight tool to achieve IRP objectives, the differences between the gas and the electric utility sectors and their implications for IRP, and finally, the relative effectiveness of various regulatory schemes to achieve IRP objectives.

The remaining chapters of the study are organized as follows. Chapter 2 provides a synopsis of the procedural, planning, and ratemaking aspects of the IRP process. The discussion also evaluates various approaches and methods used in the IRP process. Chapter 3 contains a detailed examination of the basic rationale and important issues underlying the IRP process. The examination addresses both generic issues and issues specifically applicable to LDCs. The issues examined include energy efficiency, cost minimization, and the role of IRP in the new gas industry structure. Chapter 4 develops

7 XENERGY Inc., DSM Program Evaluation: Background, Concepts, and Issues for Public Utility Commissioners (Boulder, CO: XENERGY, February 1994). 
a policy framework to guide regulatory choices for achieving IRP objectives. Based on this framework, various regulatory options and mechanisms are examined. Chapter 4 concludes with a set of recommendations that could be used by PUCs to develop regulatory approaches that can facilitate IRP objectives under the new competitive environment in the gas industry. 


\section{CHAPTER 2}

\section{IRP FOR THE LDC: A SYNOPSIS OF CURRENT AND EMERGING PRACTICES}

The IRP process is being increasingly adopted for LDCs and closely mirrors a process that has been extensively used for electric utilities. The form of the IRP process varies somewhat across state PUCs. ${ }^{1}$ The IRP process embodies three basic elements: (1) planning and implementation of the IRP by the utility in several stages, (2) regulatory or administrative procedures used by the PUC to review the utility plan and monitor its progress, and (3) ratemaking approaches to better promote IRP objectives. ${ }^{2}$

\section{Planning and Implementation of an IRP}

The planning and implementation of a utility IRP involves several stages. They are: (1) developing a resource plan, (2) submitting the plan for regulatory review or approval, (3) carrying out the plan while monitoring its performance, and finally (4) modifying the plan for future implementation based on the information generated by stage 3 .

Developing a resource plan itself involves several tasks. The utility makes a forecast of future demand over the planning period. The baseline forecast generally assumes no additional use of DSM options. Another forecast may include the effect on gas demand of implementing DSM options. The difference between the demand forecasts reflects estimates of potential gas savings. The modified forecast, which includes the effect of DSM, is used to develop a mix or portfolio of supply side options.

1 For updated reports on state IRP processes for LDCs, see the periodical Gas IRP Review, published by the Gas Research Institute.

2 For a comprehensive overview of the IRP process for the gas LDCs, see NARUC, Primer on Gas Integrated Resource Planning (Washington, D.C.: NARUC, December 1993). 
The mix of demand- and supply side options is then used to project utility costs. In arriving at the desired resource mix, the LDC also attempts to minimize some chosen cost criterion, such as the present value of revenue requirements over the planning horizon, while ensuring an adequate level of reliability. The final task consists of determining the rate impact on different classes of customers using prescribed or allowed rate-design methods. The resource mix, the corresponding estimates of costs (the total cost as well as the costs of individual demand- and supply side options), and rate impacts constitute the final IRP.

Once an IRP is developed, it is submitted for review and/or approval by the PUC. At this stage, intervenors representing various stakeholders (different customer classes, environmental groups, and so on) are allowed to respond to the LDC filing. ${ }^{3}$ Finally, the PUC may either allow the LDC to implement the IRP with or without modification. Review and/or approval of future siting of facilities, gas supply contracts, and other LDC actions may be contingent upon prior disposition of the IRP.

The next stage is the actual implementation. At this stage, the performance of various options included in the IRP may be closely monitored. Of particular interest are DSM options, or DSM programs that may combine several options. The monitoring activity is generally performed by the LDC itself and may be subject to reporting requirements sanctioned by the PUC. For DSM options or programs, participation rates, consumption patterns, and the resulting load profiles are parameters of interest that may be monitored for agreement or deviation to projected estimates. The evaluation of supply side options, however, generally does not require such close monitoring; they are addressed in traditional regulatory mechanisms such as rate hearings and purchased gas adjustment (PGA) hearings.

The last stage of IRP implementation consists of two components: addressing the "lessons learned" from prior implementation; and making appropriate adjustments in

3 It is common for various stakeholders to be involved in the development phase of the IRP before the plan is filed for PUC review. 
developing and implementing a future IRP. The prior implementation experience, for example, may provide indications as to the relative effectiveness of various options and help weed out the least effective ones. The experience becomes part of the collective knowledge of the LDC, the PUC, and other stakeholders; it also may provide guidance to other states in developing and implementing IRPs.

In developing a resource plan as well as monitoring its performance, there are two key issues: (1) the choice of cost criterion used to evaluate an IRP and (2) the choice of methods to evaluate the cost-effectiveness of various DSM options or resources ${ }^{4}$ to be included in the IRP.

\section{The Cost Criterion for IRP}

As mentioned, the IRP process seeks to achieve a multiplicity of objectives including minimizing resource costs, meeting reliability standards, and addressing rateimpact issues. ${ }^{5}$ Among these, cost minimization is one of the primary objectives and merits special attention. The choice of cost criteria is critical to the effectiveness of the IRP process. Cost criteria that have been proposed or used include the total utility cost, the total resource cost, the nonparticipant cost, and the total societal cost. ${ }^{6}$ These cost criteria are generally used in cost/benefit tests to evaluate alternative DSM resources.

4 The phrase "DSM resource" is generally used by IRP analysts to indicate either a single DSM option, a combination of DSM options, or a comprehensive DSM program.

5 For a comprehensive definition of IRP objectives, see Benjamin F. Hobbs, "The 'Most Value' Test: Economic Evaluation of Electricity Demand-Side Management Considering Customer Value," The Energy Journal 12, no. 2 (1991): 67-91.

6 The cost criteria are generally defined in terms of cost/benefit tests. For overviews of cost/benefit tests, see NARUC, Primer on Gas Integrated Resource Planning; and RCG/Hagler, Bailly, Inc., Integrated Plar ning, DSM Evaluation and Cost Recovery Issues (Washington, D.C.: American Gas Association, May 1991). 


\section{The Utility Cost}

The total utility cost may be defined as the total cost to the utility of all supply side and DSM resources. The total utility cost criterion includes the cost-reducing effect of DSM resources on supply side resources. For example, a customer rebate program for efficient appliances adds to utility costs in the form of administrative costs (including the rebate) and installation costs (if the utility installs the appliances). However, the same program may reduce future supply and transportation costs, storage-related costs (construction, leasing, and operations), and distribution costs. The avoided cost of supply resources offsets the direct costs the LDC incurs by adopting a DSM resource. The utility cost is the net cost of adding a resource to the resource mix, which is the difference between the direct DSM resource costs and the avoided supply side costs. Similarly, the net benefit can be defined as the difference between the avoided costs and the direct DSM costs. A DSM resource may be considered cost-effective if the net benefit is positive. DSM resources can be ranked by the magnitude of the net benefit. The greater the net benefit, the more cost-effective is the DSM resource.

\section{The Total Resource Cost}

The utility cost criterion, however, may not correctly measure the cost of total resources used in the IRP process. A correct measure of this cost should include any additional costs incurred by any party when the utility supplies a resource. For example, participants in a conservation program may have to incur expenditures to supplement expenditures made by utilities. These costs should be added to the utility's direct conservation resource costs to calculate the total conservation costs. The utility cost and total resource cost criteria are most often used by PUCs to assess the cost-effectiveness of DSM options. 


\section{The Nonparticipant Cost}

The nonparticipant cost criterion calculates the net effect of DSM resources on ratepayers not directly benefiting from those activities. Under the assumption that the utility is able to recover from ratepayers lost profits attributable to DSM resources, nonparticipants may incur higher-than-otherwise rates. For example, when the utility's lost revenues exceed its avoided costs (net of the utility's direct DSM costs), nonparticipants would be worse off (relative to other resource options) as the utility increases its rates to remain financially whole. Consequently, nonparticipants in a DSM program may experience an increase in their rates and bills. Nonparticipants, however, may achieve some savings in the long run because of the deferral or avoidance of supply side costs.

The nonparticipant cost may be used as an independent criterion to test the social desirability of DSM resources; the corresponding cost/benefit test is known as the rateimpact measure (RIM) test. ${ }^{7}$ Compared to the other tests, it is generally more stringent in terms of supporting DSM resources.

\section{The Societal Cost}

The utility cost, the total resource cost, and the nonparticipant cost criteria all include only private costs incurred by various parties involved in the IRP process. None of the three cost criteria incorporates the social costs or externalities resulting from the supply and consumption of gas. The societal cost criterion incorporates externalities to determine all costs resulting from the supply and the consumption of gas. The definition of cost-effectiveness of a DSM resource can be further extended to include externalities. The extended definition uses the societal cost rather than the other cost criteria as the criterion by which to evaluate and rank resource options.

7 The RIM test is also known as the "no losers" test. 


\section{Comparison of Cost Criteria}

One of the important differences among the four basic cost criteria lies in how each criterion can be viewed from the perspectives of different stakeholders. The simplest among the four, the utility cost, includes only the direct costs to the utility. This criterion does not incorporate additional costs incurred by DSM participants and the revenue-reducing effects of DSM resources. If this criterion is used to select a resource plan, the utility is less likely to choose DSM resources that would be the most effective in reducing demand; this would obviously defeat one of the important purposes of the IP.P process. To counter this disincentive for adopting DSM resources, many PUCs have instituted mechanisms that allow the utility to recover the lost revenues by adjusting customer rates.

If the direct costs incurred by participants is added to the direct utility costs, the sum becomes the total resource cost. The total resource cost includes private costs incurred by both the utility and direct beneficiaries of DSM resources. Application of the total resource cost criterion, however, to IRP may introduce equity problems. A plan meeting the cost-effectiveness test based on the total resource cost criterion may reduce total bills (due to a reduction in consumption) to one class of customers (participants in a DSM program) and raise rates (to recover DSM program-related costs including rebates, and also to recover lost revenues) and total bills to another group of customers (nonparticipants in a DSM program). It can be argued that although rates to nonparticipants may have to be raised in the short run to implement a DSM program, long-run energy costs to the same customers may be lower to the extent the utility is able to avoid or defer supply side costs.

In spite of the potential for long-term cost savings, the uncertainties inherent in evaluating energy savings and avoided costs, as well as the issue of customer choice, make the equity issue contentious between the participant and nonparticipant perspectives. The nonparticipant cost criterion can help to avoid this equity problem. In comparison with the other cost criteria, however, it would likely lead to utilities expending the least effort toward DSM activities. 
If the environmental and externality costs are added to the total resource cost to arrive at the total social cost as a basis for IRP, the issues become more complex. Added to the other uncertainties, related to the evaluation of energy savings ${ }^{8}$ and avoided costs, are the unavailability of well-accepted methods of measuring externality effects and the issue of whether the regulatory process is the appropriate public intervention vehicle and whether the ratemaking mechanism is the most effective instrument for internalizing the externalities.'

As the foregoing discussion indicates, the choice of any of the cost criteria as the basis of an IRP involves issues such as economic efficiency, equity among parties, financial health of the utility, and the broader issue of the appropriate public policy role of the PUC. These issues, which are germane to the IRP process, are not amenable to simple resolution: they have been extensively analyzed and debated over the past decade, and should undergo reexamination in the light of developments and changes in the energy industry.

\section{Methods of Evaluating DSM Resources}

One of the key issues that may get close attention in IRP hearings is the methods and data used in estimating energy savings and costs achieved by a given DSM resource. For example, installation of energy-efficient appliances may lead to a reduction of both volumetric and peak consumption of gas, which in turn reduces the contract demand, gas

${ }^{8}$ For a discussion of measurement problems associated with energy savings and avoided costs, see Phoebe Caner, "The Drive to Verify Energy Savings," The Electricity Journal 5, no. 4 (May 1992): 44-52; and Paul L. Joskow and Donald B. Marron, "What Does a Negawatt Really Cost? Further Thoughts and Evidence," The Electricity Journal 6, no. 6 (July 1993): 14-26.

9 Chapter 3 examines the public policy role of PUCs in mediating externalities arising from operation of regulated utilities. 
take from suppliers, contract transportation capacity, and throughput from pipelines. The ultimate result is a reduction of the costs of gas supply to the utility. However, there are costs associated with installing efficient appliances. These costs may be shared between the utility and the end-use customer. There may be additional costs associated with program administration, marketing and customer education, besides costs directly attributable to the installation work.

A key question is whether the costs of implementing a DSM option or program are lower than the avoided supply costs. An accurate calculation of the avoided supply costs, therefore, is critical to determining the cost-effectiveness of a DSM option or program. Several methods are currently in use for calculating avoided gas supply costs. $^{10}$ They include (1) the system marginal-cost method, (2) the generic proxy method, (3) the targeted marginal-cost method, and (4) average-cost methods.

\section{The System Marginal-Cost (SMC) Method}

The SMC method attempts to calculate the change in system fixed and variable costs corresponding to a change in demand. There are three known methods of calculating the system marginal cost. The instantaneous method calculates the change in the system cost for a small or theoretically infinitesimal change in demand resulting from a DSM program. This method essentially calculates the cost reduction achieved by avoiding the use of the most expensive supply side resources at the margin; it measures short-run avoided cost. The increment/decrement method calculates the change in system cost for a discrete (not infinitesimal) change in demand. This method recognizes that demand reductions may occur in blocks of significant size as a result of DSM programs and that the marginal cost curve is lumpy rather than continuous. The differential

${ }^{10}$ For overviews of avoided cost estimation methods, see NARUC, Primer on Gas Integrated Resource Planning; and RCG/Hagler, Bailly, Inc., Integrated Planning, DSM Evaluation and Cost Recovery Issues for Gas Distribution Utilities. 
revenue requirements method is a variant of the increment/decrement method that calculates the fixed and variable components of the system avoided cost separately.

\section{The Generic Proxy-Cost (GPC) Method}

In the GPC method, the avoided supply resource being considered is not necessarily the resource being used at the margin. Instead, it is the resource that will be displaced by the DSM resource corresponding to a specific type of load. For example, if the load being displaced is not sensitive to weather or ambient temperature (such as an efficient water heater), the proxy resources are supply contracts designed to serve high load-factor demand. On the other hand, if the load being displaced is temperaturesensitive, such as through improved insulation, the proxy resources are supply contracts designed to serve low load-factor demand. It is possible for the system supply cost method and the generic proxy method to yield the same results if the proxy resources being considered also happen to be the resources at the margin.

\section{The Targeted Marginal-Cost (TMC) Method}

The TMC method combines elements of both the system marginal cost method and the generic proxy method. Like the system marginal cost method, it attempts to estimate the cost of supply sources avoided at the margin. Unlike the system marginal cost method and like the generic proxy method, the TMC method does not attempt a complete simulation of system costs. Instead, it uses the costs imposed by chosen blocks of load (at the margin) which could be avoided by a selected quantity of a DSM resource. Essentially, the TMC method attempts to estimate the marginal cost by using the generic proxy method with the most expensive supply resources as the proxy. This is based on the reasoning that such resources are needed to meet the marginal loads. Since this method does not perform a complete simulation of the system cost, the choice of proxy resources at the margin is critical to the accuracy of results. 


\section{Average Cost Methods}

Avoided supply costs can also be calculated on the basis of average costs. Average cost methods are simple to use and have extensively been used in traditional utility planning and ratemaking. Typically, the average cost can be calculated by summing the cost contribution of each resource to the supply mix and dividing by the total volume of gas supplied. The cost contribution of each resource is the unit cost of the resource weighted by its volumetric contribution to the supply mix. The average cost thus obtained is also known as the "weighted average cost" of gas.

\section{Comparison of Evaluation Methods}

The various methods that can be used to calculate avoided supply costs vary with respect to computational effort, accuracy and dependability of results, and degree of applicability to IRP analysis. The system marginal cost represents the correct economic index of avoided supply costs; it relies the least on the subjective judgement of the analyst. The SMC, however, which requires extensive data preparation and a complex computational model, may be highly sensitive to small differences in data assumptions. The generic proxy method, which relies on the analyst's ability to match DSM resources and proxy supply resources, may be subject to significant potential errors. The TMC method relies even more heavily on user judgment and therefore, may be subject to larger errors than the GPC. ${ }^{11}$ Both the GPC and the TMC have the advantage of computational simplicity and an intuitively clear correspondence between the DSM resource being considered and the supply resource being avoided. The average cost methods, which are the most clearly understood and perhaps subject to the least errors,

${ }^{11}$ User judgment needs to be exercised to ensure that the proxy DSM resource displaces the targeted supply side resource and also to ensure that the proxy displaces a marginal load. 
do not bear a clear conceptual link to IRP analysis. This is because the supply cost being avoided occurs at the margin and has very little to do with average supply costs.

\section{Requlatory Procedures for Administering a Utility Resource Plan}

The procedures used to administer a utility resource plan can take many forms. A PUC may require the utility to submit a resource plan that is comprehensive: the plan considers both supply side and demand-side options, accompanied by an analysis of costs of all options with due consideration for both costs to the utility and social costs. The requirement for a plan filing may be a precondition to any subsequent approval of utility investments and expenses. However, either meeting the filing requirement or obtaining PUC approval of a plan may not constitute a preapproval of future utility investments and expenses. State PUCs vary in terms of the quantity of data to be submitted to meet filing requirements, the type of regulatory proceeding used to process a utility resource plan, the form of review conducted, and the level of commitment implied by regulatory approval of the plan.

\section{Ratemaking Approaches Used to Promote IRP}

It generally is recognized that traditional regulatory practices are unlikely to encourage IRP among regulated public utilities. As previously discussed, the traditional regulatory framework is often characterized as having poor cost minimization incentives because of its general cost-plus nature and the presence of the ROR constraint, as lacking any strong incentives for DSM options because of the positive link between profits and sales, ${ }^{12}$ and as lacking any accounting of social costs.

To overcome these problems, regulatory policy analysts have proposed and many PUCs have introduced incentive mechanisms to supplement general and direct oversight

${ }^{12}$ See Chapter 3 under "IRP and the Market Failure Argument" for a discussion of the inherent conflict between selling energy and selling energy efficiency. 
procedures (such as review and approval of utility IRP filings). The incentive mechanisms include (1) recovery of direct DSM program costs, (2) adjustments for lost revenues, (3) decoupling of sales and revenues (4) shared savings of benefits, and (5) adjustments to ROR for DSM investments. ${ }^{13}$

\section{Recovery of Direct DSM Program Costs}

There are two basic methods for treating the recovery of direct DSM program costs. DSM costs can either be expensed or capitalized. Under the expensing option, DSM costs are airectly passed on to customer rates. Under capitalization, DSM costs are added to the utility rate base and depreciated over a period of several years, with the utility allowed to earn a return on the undepreciated portion each year.

The above treatments represent traditional practices used respectively for consumable, low expense resources, and long-lived, expensive assets. Such treatments have their justification in the generally good correspondence between the acquisition cost, the economic life, and the service duration of supply side resources. For example, a unit of the gas commodity represents a low-expense resource that provides an energy service for a short time; therefore it qualifies for the expensing rate treatment. A pipeline, however, is a high-cost and long-lived asset that provides an energy service over its life. Many DSM resources defy such clear classification. For example, expenditures to disseminate information on DSM options can be either high- or low-cost, do not have a clearly defined economic life, and may affect energy savings over a long period of time. The ratemaking treatment of DSM resources may be based on considerations of magnitude and the duration of potential benefits.

${ }^{13}$ For detailed overviews of ratemaking mechanisms used to recover DSM expenses for electric utilities, see Steven Nadel, Michael Reid, and David Wolcott, eds., Regulatory Incentives for Demand-Side Management (Washington, D.C.: American Council for an Energy-Efficient Economy, 1992). 
Expensing DSM resources is straightforward and presents few accounting problems. Expensing, however, may cause rate fluctuations that may be unacceptable to affected parties. Expensing also may put DSM resources at a disadvantage relative to supply side resoul ces. Ratebased supply side resources earn a return on utility investments. If DSM resources are not afforded the ratebase treatment and therefore do not earn a return, this may create a preference of supply side resources.

Capitalization or ratebasing of DSM resources "levels the playing field" for such resources. However, relative to the expensing treatment, there may be greater accounting effort associated with determining the appropriate depreciable life and estimating carrying charges. ${ }^{14}$ Also, if the allowed ROR on DSM resources is the same as for supply side assets, there is no clear incentive for the utility to pursue DSM options. Capitalization merely removes a disincentive but does not necessarily provide a positive incentive for pursuing DSM options.

Finally, neither accounting treatment of DSM costs provides any clear incentive to the utility to minimize costs and to choose cost-effective DSM options. Therefore, such cost recovery mechanisms need to be either substituted or supplemented with other mechanisms that reward the utility for cost-effectiveness.

\section{Adjustments for Lost Revenues}

Recognizing the fact that adoption of cost-effective DSM options may lead to a reduction of sales, and therefore, a reduction of revenues and profits, mechanisms to compensate the utility for lost revenues have been proposed and used. Such mechanisms were used in the past for electric utilities and have also been proposed for LDCs. The basic mechanism consists of estimating the net lost revenues, recording the amount in a

${ }^{14}$ Carrying charges include taxes and interest accruing on investments and assets after assets have been put into service. 
balancing or adjustment account and applying a "true up" procedure to adjust rates in a future period.

Cost-effective DSM measures affect utility' revenues and profits in several ways. ${ }^{15}$ A reduction of consumption causes a direct reduction of sales, and a corresponding reduction of revenues. Even assuming that the LDC can recover all prudently-incurred costs, including DSM expenditures, the reduced revenues also lead to reduced profits in the short term. On the other hand, the reduced consumption also allows the LDC to defer supply contracts and other supply side investments, and achieve a reduction of long-term costs; this leads to a positive contribution to the profit margin. ${ }^{16}$ However, the loss of profits due to short-term sales reductions may offset any gain in profits due to long-term cost reductions. Given the fact that long-term cost reductions are generally less certain than short-term sales loses, the utility may not be motivated to pursue truly cost-effective DSM measures. The above observations argue for compensating the utility for net lost revenues.

The first step in implementing a net lost-revenue adjustment (LRA) mechanism is the difficult one of correctly estimating the net lost revenues attributable to DSM measures. Estimations of both the lost sales and avoided supply costs constitute formidable challenges. ${ }^{17}$ The critical variable that needs to be estimated is the gas savings achieved by DSM measures. The estimation of this measure is subject to uncertainties in projecting the baseline forecast of gas consumption (in the absence of DSM measures), either by estimating future gas consumption (using engineering models) or by measuring actual gas consumption (as it occurs) as a result of adopting DSM

${ }^{15}$ Cost-effectiveness, as previously defined, measures the difference between cost savings and costs resulting from alternative resource choices.

16 This assumes that regulatory lag allows the utility to retain excess profits resulting from cost reductions.

${ }^{17}$ NARUC, Primer on Gas Integrated Resource Planning, 235. 
measures. ${ }^{18}$ The estimated savings is the difference between the baseline forecast and either the estimated or measured consumption. One difficult task in the estimation is isolating the effect of DSM measures on consumption (whether estimated or measured). Sources of difficulty include the potential for market-induced DSM adoption even in the absence of utility initiative (the "free-rider" problem) and the potential for an increase in gas consumption by some customers that offsets any reduction owing to use of energyefficient appliances (the "rebound" effect). Other sources of uncertainty in estimating net lost revenues include the variability of gas prices and the discretion available to the analyst in choosing important parameters (such as a proxy supply source for a DSM resource).

An LRA mechanism strengthens the incentive in favor of DSM options. Such a mechanism, however, does not offer any clear incentives for cost minimization and should be substituted or supplemented with other mechanisms that reward cost-effective performance.

\section{Revenue Decoupling Mechanisms}

Revenue decoupling mechanisms (RDMs) are intended to make the utility indifferent between supply side and DSM options by removing the link between sales and revenues. Under traditional regulation, a utility earns higher revenues and generally higher profits from increased sales. This introduces a clear bias against resource options that are energy efficient. It is argued that RDMs have several advantages over LRA mechanisms. The most important advantage is that RDMs do not require precise estimation of net lost revenues. Another advantage is that the utility can increase its

${ }^{18}$ In the IRP literature, with rare exceptions, the two common methods of estimating energy savings are referred to as the "engineering estimate" and the "actual measurement" of "savings," although what is being estimated is not savings but consumption. The baseline forecast, which is common to both methods of estimation, is subject to uncertainties and, therefore, neither method provides an actual measurement of savings. 
profits between successive revenue adjustment periods by minimizing costs under an RDM. This feature is clearly absent in an LRA mechanism. Therefore, unlike an LRA mechanism, an RDM rewards/penalizes the utility for the cost performance of its DSM programs.

RDMs were proposed and implemented in several forms for both electric and gas utilities. The earliest application was introduced by the California Public Utility Commission in 1976 and was called ERAM (electric revenue adjustment mechanism). ${ }^{19}$ ERAM uses a test year to determine a level of annual nonfuel revenues until the next rate proceeding. Revenues related to fuel, purchased power, and direct costs of energy conservation are collected separately. ERAM allows a utility to collect the predetermined amount of nonfuel revenues regardless of the level of sales. ERAM generally requires either frequent rate hearings or automatic revenue adjustment (attribution mechanisms) to account for deviations from forecasted revenue requirements. Although ERAM predates IRP and was not initially intended to promote DSM options, it also can promote energy-efficient investments.

Another form of RDM, used in Maine and Washington, is called RPC (revenue per customer).$^{20}$ Unlike ERAM, RPC allows revenues to grow in proportion to customer growth rather than sales growth. Therefore, the utility's revenues are not affected by changes in consumption by individual customers. Instead, revenues are affected by changes in the number of customers. The RPC mechanism, like ERAM, provides incentives for cost minimization and reduces the bias against demand-side options. The RPC mechanism may be stronger in countering the bias against conservation measures: it ties revenue growth to increases in the number of customers, on which a franchised utility may not have significant control, and does not penalize the

${ }^{19}$ C. Marnay and G.A. Comnes, "California's ERAM Experience," Regulatory Incentives for Demand-Side Management, S. Nadel, M. Reid, and D. Wolcott, eds. (Washington, D.C.: American Council for an Energy-Efficient Economy, 1992).

${ }^{20}$ David Moskovitz and Gary Swofford, "Decoupling Sales and Profits: An Incentive Approach that Works," The Electricity Journal 4, no. 6 (July 1991): 46-53. 
utility for reducing demand of existing customers through cost-effective DSM. The ERAM mechanism, on the other hand, would allow changes in revenue levels from one rate period to ancther based on both customer growth and sales growth per customer. Therefore, although an ERAM may remove the sales bias within a rate period, it does not do so between rate periods. The RPC mechanism, on the other hand, addresses the source of sales bias more directly by linking revenues explicitly to customer growth rather than consumption per customer.

\section{Shared Savings Mechanisms}

Shared savings mechanisms allow a sharing of cost savings (avoided costs) achieved by DSM options between utility customers and shareholders. ${ }^{21}$ The savings can be based on forecasted differences of energy usage (for example, the engineering estimate of energy savings) with or without DSM options, the difference between forecasted energy usage without DSM options and actual consumption data, and analysis of customer billing data.

A shared savings mechanism offers a clear incentive to the utility to undertake cost-effective DSM measures. However, like LRA mechanisms and unlike RDMs, a savings sharing mechanism is very sensitive to data and estimation procedures. Also, related concerns arise from the difficulty of separating factors (some of which may be unrelated to a utility's DSM efforts) that contribute to savings.

\section{ROR Adjustments}

As noted in a previous section, capitalization of DSM costs by itself may not induce the desired level of DSM expenditures if the ROR for DSM is the same as for other investments. One way to address this problem is to allow a higher or lower ROR

${ }^{21}$ J.H. Eto, A. Destribats, and D. Schultz, Sharing the Savings to Promote Energy Efficiency (Berkeley, CA: Lawrence Berkeley Laboratory, April 1992). 
for DSM options based on performance. ${ }^{22}$ The performance can be determined in an ex post prudence review based on either PUC discretion or on standards clearly established ex ante. Among the two, setting of ex ante standards may provide stronger incentives for adopting cost-effective DSM options.

Like the shared savings mechanisms, ROR adjustment-based incentive mechanisms are very sensitive to data gathering and savings estimation procedures used to evaluate performance.

22 NARUC, Primer on Gas Integrated Resource Planning, 241. 


\section{CHAPTER 3}

\section{IRP FOR THE LDC: AN EXAMINATION OF ISSUES}

Although IRP has gained general acceptance as a planning approach, it has been the subject of controversy. Regardless of whether one agrees with the objections raised to IRP, the underlying arguments merit careful examination by regulators. IRP objectives of energy efficiency and environmental protection are less controversial than the rationale of using the PUC, the utility, and specific regulatory policies as instruments employed to achieve these objectives. Proponents and opponents of the IRP process sometimes mix technical, and objective, analysis of underlying issues with the articulation of ideologically partisan positions. ${ }^{1}$ Regulators at state PUCs need to dispassionately examine the underlying issues and various positions advocated to deal with the issues, and to craft defensible policies that promote IRP objectives.

The issues to be examined fall into two distinct categories. First are a number of generic issues that have emerged since the beginning of IRP for electric utilities and continue to emerge and impact regulatory policy for both electric and gas utilities. A second set of issues arises from the differences between the electric and gas utilities and applicability of the electric IRP approaches and methods to gas utilities.

\section{Generic Issues}

As mentioned in Chapter 1, the IRP paradigm emerged in response to two parallel sets of developments in the electric utility industry in the late 1970s. The

${ }^{1}$ For an exchange of conflicting views on the costs and benefits of energy efficiency, see Paul L. Joskow, "More From the Guru of Energy Efficiency: 'There Must Be a Pony," The Electricity Journal 7, no. 4 (May 1994): 50-61; and Amory B. Lovins, "The Great Negawatts Debate, Apples, Oranges, and Horned Toads: Is the Joskow \& Marron Critique of Electric Efficiency Costs Valid?" The Electricity Journal 7, no. 4 (May 1994): 29-49. 
industry was experiencing the transition from a period with high load growth, declining costs, and declining prices to a period of low load growth, rising costs, and rising prices. At the same time, a growing body of academic literature emerged that examined the weaknesses and inefficiencies of economic regulation. Although analysts differed on the nature of inefficiencies, their causes, and their magnitudes, there appeared to be a general consensus that economic regulation provides poor incentives for cost minimization and efficient management. There was also a divergence of approaches that emerged in response to the incentive problems of traditional regulation. PUCs generally responded by heightening the level of scrutiny and oversight of utility operations to better protect the ratepayers' interest, while academics proposed various incentive-based approaches. ${ }^{2}$ The first approach focused on the cost-plus nature of regulation and the inadequate accountability for inefficient or imprudent management. The second approach focused on the profit constraint in the ROR feature of regulation and the weak link between good performance and reward.

IRP emerged as one variant of the first approach. Two basic differences between the tight regulation that emerged in the late 1970s and the IRP approach that replaced it lie in the relative emphasis put on the ex ante and ex post oversight and the scope of regulatory goals. In contrast to the traditional regulatory approach characterized by $e x$ post prudence and used-and-useful reviews, the IRP approach puts a strong emphasis on PUC participation in the planning phase of utility operations. The IRP approach also facilitates broader participation in the planning process by various stakeholders, including different classes of ratepayers, environmental groups, and industry groups. Further, the IRP approach is evolving in the direction of developing better utility incentives based on performance. Finally, the IRP approach attempts to facilitate a greater role for demandside and energy efficiency options in a utility's resource mix.

${ }^{2}$ For an overview of regulatory changes in the 1970 s and incentive-based regulatory approaches, see Paul L. Joskow and Richard Schmalensee, "Incentive Regulation for Electric Utilities," Yale Journal of Regulation 4, no. 1 (Fall 1986): 1-49. 
The foregoing discussion summarizes the defining characteristics of the IRP approach in the regulatory process. The issues that IRP has attempted to address include cost minimization, energy efficiency, cost allocation and equity, competition, and externalities.

\section{IRP and Cost Minimization}

The movement toward IRP was partly in response to the weak cost-minimization incentives inherent in traditional regulation, a point on which both proponents and opponents would tend to agree. Beginning in the early 1960s, economists have identified several features of regulation that may induce the utility to make inefficient resource acquisition choices and facilitate inefficient management of operations. In a seminal work, Averch and Johnson pointed out that if the market cost of capital (COC) the utility uses to acquire inputs were to fall below the regulated ROR, the utility would be likely to inefficiently choose capital-intensive resources over others (the A-J effect). ${ }^{3}$ An obvious corollary of this observation is that if the COC were above the ROR, the opposite, and still inefficient, outcome is likely to occur. In this case, the utility is likely ' choose less than an optimal level of capital in its input mix. The A-J effect appeared to explain, to a large degree, the extensive amount of capital-intensive construction that occurred throughout the 1960 s and early 1970 s.

A number of other features of utility regulation have been identified as sources of inefficiency. The cost-plus nature of regulation, which allows the utility to pass through all prudently incurred expenses, is believed to make the utility indifferent to the relative costs of acquiring inputs (such as fuel) and less than diligent in managing its operations. This particular feature of regulation was exacerbated by the introduction, as a response to the financial instability threatening utilities in the early 1970s, of fuel adjustment

${ }^{3}$ H. Averch and L. L. Johnson, "Behavior of the Firm Under Regulatory Constraint," American Economic Review, 52 (December 1962): 1052-69. 
clauses (FACs) and purchased gas adjustment clauses (PGAs). ${ }^{4}$ FACs and PGAs allow a utility an automatic adjustment of rates, without a formal regulatory hearing, in response to changes in fuel prices. Such an adjustment reduces the cost of frequent regulatory hearings, prevents large rate shocks, and stabilizes utility earnings. The adjustment, however, tends to make the utility less than diligent and efficient in fuel procurement decisions. ${ }^{5}$ Furthermore, the ex post review of utility decisions and the potential for cost disallowances may make the utility err on the side of caution and lead to an inefficient avoidance of risk. This focuses the utility decisionmaking more toward regulatory cost recovery and away from innovation. Finally, regulation is also perceived by utilities, with good reason, to be asymmetric with respect to the risk/reward structure. Rewards for good performance are limited by the profit constraint, the allowed ROR. Penalties for bad performance or pure "bad luck" (through application of the used-anduseful standard) are also limited but may be perceived as disproportionately larger than corresponding rewards for good performance. Combined with the retrospective focus of regulatory review, the asymmetric risk/reward structure further inhibits efficient and innovative decisionmaking.

IRP attempts to address some of the incentive problems of traditional regulation. The capital bias underlying the A-J effect is countered by having the utility focus more on energy efficiency and conservation and less on energy generation and supply. The IRP approach treats the role of the utility as one of supplying "energy services" rather than energy and deemphasizes the building of large and capital-intensive energy

4 Although conditions prevailing at the time, recession, fuel shortages and volatile fuel prices, did perhaps justify the introduction of FACs and PGAs, continuation and persistence of these regulatory practices, in view of vastly changed energy industry, needs to be seriously reexamined, regardless of how other regulatory issues are viewed.

5 For a discussion of incentive problems associated with PGAs, see Robert E. Burns, Mark Eifert, and Peter Nagler, Current PGA and FAC Practices: Implications for Ratemaking in Competitive Markets (Columbus, $\mathrm{OH}$ : The National Regulatory Research Institute, December 1991). 
production facilities. ${ }^{6}$ The disincentive for efficient fuel procurement present in FAC's and PGAs is partly countered by the energy efficiency focus of the IRP approach. The risk averseness caused by the practice of retrospective reviews is addressed by the ex ante and participatory planning process of IRP. Finally, many of the IRP methodologies currently practiced or proposed attempt to tie rewards and penalties to utility performance in ways that may be considered more equitable and symmetric. However, PUCs may wish to refashion their overall regulatory focus and the associated administrative and ratemaking approaches in response to rapidly developing gas commodity markets. This may require a greater degree of attention to supply side resource-acquisition issues.

One such important issue that merits greater attention in discussions of IRP is supply side resource optimization. The focus on even treatment of demand- and supply side resources seems to relegate the discussion of supply side resource optimization to a position of peripheral significance. If one of the aims of IRP is to achieve a least-cost mix of resources to deliver energy services, one needs to point out, somewhat ironically, that both the demand-side and the supply side must receive equal attention. Otherwise, it is possible to develop, at the extreme, a resource plan that combines an efficient mix of demand-side resources with an inefficient mix of supply side resources.

Although the above imbalance in focus, which occurs at the stage of regulatory discourse, is somewhat compensated at the stage of planning analysis by conducting "resource integration" exercises, such an imbalance can shade regulatory policy in unintended ways. The "integrated" resource plan generated at the planning stage by itself does not guarantee that the intended objectives will be achieved unless regulatory policies for both the demand side and supply side have the appropriate incentives to ensure efficient implementation. This is especially true for the LDC, which is faced with many opportunities and risks in the emerging gas commodity markets. In the absence of appropriate incentives, an LDC may not exercise appropriate levels of diligence and

6 See the following section, "IRP and Energy Efficiency," for a discussion of the energy service concept. 
entrepreneurship in its gas procurement decisions; consequently, it may not acquire a least-cost portfolio of gas supplies.

A related issue is the congruence of demand-side and supply side regulatory policies. In other words, as much as a utility should combine resources in an integrative framework, there is also a need to combine regulatory policies for the demand-side and the supply side in an integrative framework to ensure that the desired plan will be implemented efficiently.

\section{IRP and Energy Emciency}

A major objective of IRP is to promote more efficient production, transmission, and consumption of energy. The IRP approach is predicated on the premise that energy ought to be produced, supplied, and consumed with the least achievable expenditure of primary energy resources, especially those resources that may be considered depletable or nonrenewable (coal, gas, uranium, and so on). Within the various components of the energy delivery system, the IRP approach has traditionally focused on consumption or end-use efficiency. Improving the efficiency of the transmission and distribution (for example, through the use of improved transformers in the case of electric utilities) process has also received some attention. In dealing with production efficiency, IRP proponents tend to iavor the increased use of renewable resources to displace fossil and other depletable resources; less attention is generally paid to more efficient utilization of fuel or depletable resources.

The underlying rationale of IRP for promoting energy efficiency is to achieve the desired level of energy service at the least societal resource cost. In this respect, the IRP approach departs fundamentally, both with respect to how the energy product is defined and what constitutes "cost," from much of traditional and mainstream thinking. According to the IRP paradigm, traditional and mainstream thinking about what is being provided by energy utilities contains a fundamental flaw. A common understanding regards utilities as supplying and customers as consuming units of energy (kilowatthours $(\mathrm{kWh})$ or therms). However, the value of the product being supplied should be defined 
in terms of the satisfaction or utility being gained by the consumer. Such satisfaction should correctly be defined as the level of comfort or some other function being supplied by various devices converting energy to a usable form. In the case of an electric light bulb, for example, customers receive satisfaction from consuming "lumens" (units of lighting) rather than $\mathrm{kWhs.} \mathrm{In} \mathrm{the} \mathrm{case} \mathrm{of} \mathrm{a} \mathrm{gas} \mathrm{furnace,} \mathrm{as} \mathrm{another} \mathrm{example,} \mathrm{customers}$ receive satisfaction from consuming "joules" (units of heating) rather than therms (units of gas, defined by heat content). Most of the energy efficiency technologies seek to achieve improved energy conversion using fewer units of energy to deliver the same amount of energy service. For example, an efficient light bulb produces more lumens of lighting per $\mathrm{kWh}$ of electrical energy than a conventional light bulb; and an efficient furnace produces more joules of heating per therm of gas than a conventional furnace.

Yet, traditional thinking about the energy delivery process defines the value of the energy product in units of energy delivered rather than in units of energy service received. Such thinking, it can be argued, leads to an undervaluation of energy efficiency. ${ }^{?}$

The energy efficiency goals are indeed worthwhile and merit favorable consideration in the regulatory process. The underlying energy service concept contains an unassailable logic: in an ideal situation, utilities would price their products in units of energy service and at marginal cost. The role regulatory ratemaking can play to move toward more efficient pricing of the energy service product should be carefully examined. Like other IRP issues, there are alternative viewpoints on how to price the energy service product. Each of these riewpoints assume a different approach to another fundamental ratemaking issue, the equity among different groups of customers.

7 James J. Piepmier et al., "Sell Lumens, not Kilowatts: The Future for Electricity," The Electricity Journal 6, no. 3 (April 1993): 34-39. 


\section{IRP Ratemaking, Cost Allocation and Equity}

Most of the IRP processes currently in practice tend to spread the costs related to DSM programs among all customers, regardless of their level of participation in such programs. This raises the issue of whether costs imposed by the participants of a DSM program on the system, who directly benefit from the program, should be shared by nonparticipants, who do not. Such an allocation of costs raises a potentially significant equity problem of rates not reflecting cost responsibility.

Regarding the cost allocation of DSM programs, it can be argued that as long as the total resource cost to the utility and customers is lower for a certain program than the avoided cost of supply side resources, such cost allocation is defensible. It also can be argued that although DSM programs may raise rates to nonparticipants, the rates could have been comparable or higher if the alternative resource options from the supply side were chosen. In other words, although a DSM program may cause unequal and in some cases opposite changes in energy bills among participating and nonparticipating customers, both may be better off, and certainly society is better off, than if the alternative, supply side resources were chosen. This may be especially true if long-run rather than short-run avoided costs are considered. These arguments can be countered by pointing out the possibility that a cost allocation based on cost responsibility could achieve the same objectives if the DSM program were truly cost-effective. ${ }^{8}$ The relative strengths of these opposing arguments depend strongly on the accuracy of cost-savings estimates, which, as previously discussed, are hard to achieve.

The difficulty regarding the cost allocation of DSM resources should be addressed in the context of broad regulatory goals and emerging trends in the energy industry. The original regulatory mandate requires the regulatory commission to ensure least-cost and reliable supplies of gas. Also, regulators have traditionally attempted to balance the

8 For a detailed exposition of this view, see Larry E. Ruff, "Equity vs. Efficiency: Getting DSM Pricing Right," The Electricity Journal 5, no. 9 (November 1992): 24-35. 
interests of various parties affected by the ratemaking process. The goals of cost minimization, reliability, and equity among parties may not be completely congruent and may in certain instances be conflicting. The regulator generally attempts to arrive at a satisfactory resolution of conflicts among regulatory goals that ensures a desired level of acceptance among affected parties.

Based on the foregoing observations, it is reasonable to conclude that resource options chosen under an IRP process should meet a minimum level of reliability and an acceptable level of ratemaking equity among different classes of customers. This is particularly true if customers who perceive inequitable treatment also have options to bypass the utility's services, as is true of large industrial and other noncore customers of the LDC. It also may be increasingly true of large customers of the electric utility because of the opportunities of retail wheeling that may be forthcoming. Therefore, a regulatory authorization of cost shifting based on broad resource efficiency goals may be unworkable as nonparticipating customers capable of switching fuels or switching energy service companies leave the host utility. In such an environment, fixed system costs may be shifted to captive or core customers, many of whom may not be participants. Also, if the core customers have any price elasticity, consumption of both energy and DSM services may decrease. This would financially hurt the utility.

Given the above scenario, which is certainly plausible in view of the growing competition and unbundling of services in the energy services sector, an IRP should be more sensitive to rate impacts than was previously necessary. More importantly, these developments also merit a thorough reexamination of the basic rationale of the IRP process in the emerging competitive market environment.

\section{IRP and Competition}

The IRP paradigm was contrived to improve the performance of the traditional regulatory process. As such, the movement toward IRP constituted an incremental reform rather than a radical transformation of the traditional regulatory process. Traditional regulation itself was based on the rationale that energy and other public 
utilities behave like natural monopolies that, if left unregulated, would produce an output below the efficient level and at a price above the efficient level. The increasing level of competition in the energy industry weakens the natural monopoly argument germane to public utility regulation; as a logical corollary, competition weakens the rationale for commission participation in a utility's resource planning process under the rubric of public utility regulation.

Therefore, on pure economic efficiency grounds, PUCs should consider moving toward less regulation to facilitate the movement toward greater competition in the energy industry. In many respects, a participatory or interventionist IRP process can either impede competition, especially when customer choices are obstructed, or be ineffective or redundant when customers have options to override the intended purposes. Furthermore, such a process may constrain the flexibility of the utility in making resource acquisition and deployment choices. This would compromise the competitive position of the utility, which in turn may hurt the captive or monopoly services customers.

A PUC can facilitate IRP objectives without pursuing an overtly interventionist approach. The PUC may be able to develop regulatory approaches that integrate procompetitive goals with IRP objectives. This requires the introduction of incentives in the regulatory process that allows the utility to pursue energy efficiency, environmental quality, and service reliability without sacrificing competitiveness. One of these goals, preserving or improving environmental quality, merits a discussion of the regulatory treatment of environmental externalities and other social costs.

\section{IRP and Externalities}

The economic literature recognizes that a market, whether regulated or not, may fail to allocate resources efficiently because of the presence of externalities. An externality may be defined as a cost for which an economic agent is not compensated or a benefit for which the agent does not pay. Many of the public goods (such as the aesthetic satisfaction provided by a publicly accessible park) or the public "bads" (such as the pollution emitted by a manufacturing plant that affects neighboring populations) may 
be characterized as externalities. ${ }^{9}$ Energy utility systems may be considered sources of externalities because such systems produce pollutants and other environmental hazards in one or more stages of the energy delivery process. Unless some institutional or social arrangement can effectively mediate the dispensation of externalities, the production and consumption of goods and services may be inefficient.

The earliest known analysis of externalities was done by Pigou who argued that taxation can ration negative externalities. ${ }^{10}$ Later, Coase pointed out that an externality is bidirectional: from the perspective of economic efficiency, the roles of the beneficiaries and victims of externalities are reversible. ${ }^{11}$ For example, if a tax is levied on a polluter to compensate the victims of pollution, the polluter is being asked to forego a portion of his earnings not achieved through the mediation of a market. According to Coase, a better solution would be to let the polluter and its victim mediate an exchange by mutual consent. Either the polluter can pay the victim to gain his approval for continuing the pollution-producing activity or the victim can pay the polluter to reduce or stop the pollution. Coase's solution to the problem was for the government to define the property rights (which may legally entitle the polluter to continue its activity or entitle the victim protection from pollution) so that one or the other form of exchange may take place. Coase argued that, from the perspective of economic efficiency, it should make no difference which form of exchange took place as long as the exchange was voluntary. One problem with applying Coase's approach in the real world, by Coase's own admission, was that it fails to account for the transaction costs of the exchange. Another problem is that the Coase prescription fails to account for income distribution and equity effects that cannot be ignored in establishing social policies.

9 Public goods constitute one form of externalities. Other forms of externalities include resources with common or nonexclusive property rights. See Alan Randall, "The Problem of Market Failure," Natural Resources Journal 24 (January 1983): 130-48.

${ }^{10}$ A.C. Pigou, The Economics of Welfare, Fourth Edition (London: MacMillan and Co., Limited, 1932 (reprinted 1952)).

${ }^{11}$ Ronald Coase, "The Problem of Social Cost," The Journal of Law and Economics 3 (October 1960): 1-44. 
Other economists have addressed the externality issue and proposed several ameliorative measures, including variants of the Pigouvian or the Coase prescriptions. In addressing environmental externalities, these proposals take the form of either limiting the level of pollutant emissions or levying a charge per unit of pollutant emission (also known as an effluent fee), depending on the nature of the externality. ${ }^{12}$ One difficult issue is determining the cap on the "acceptable" level of pollution for setting a pollution limit, or alternatively, determining the "optimal" charge per unit of pollution for setting a pollution fee. Either of these determinations requires an acceptable estimate of the marginal damage caused by a unit of pollution. Another difficulty is the disagreement that might ensue among various parties about the true value (in terms of willingness to pay or willingness to be paid) of the marginal damage.

Since the inception of the externality issue, public intervention to address the issue has taken one of several forms. They include public funding (direct subsidies, loans, and grants) for activities that are perceived to enhance welfare (create jobs, advance technology, provide health benefits, and so on) and taxation or restrictions on activities that are perceived to diminish welfare (access to and use of "common property resources" such as land, water, and so on, and environmental pollution). To address environmental externalities in particular, direct restrictions on the level of pollution have generally been used. The Pigouvian prescription of taxation based on the level of pollution or the Coase prescription of assigning clear property rights to facilitate subsequent trade, or any of their variants, has rarely been used. However, the passage of the Clean Air Act Amendments of 1990 represents a major instance of mediating an environmental externality through a combination of direct restrictions and trading opportunities.

${ }^{12}$ For an overview of public policy options to address environmental externalities, see Robert Dorfman and Nancy Dorfman, eds., Economics of the Environment (New York: W.W. Noton and Company, 1993). 
Addressing externalities through the ratemaking process under PUC regulation represents a relatively recent and novel experiment. PUC regulation has generally attempted to treat two different types of externalities. The first type involves the support for the local economy or other local interests. Economic development rates to retain and attract industries to the state, low-income assistance to address poverty, and preferential treatment of certain resource choices to support local jobs are examples of this type of PUC policy intervention. The second type involves an attempt to address environmental externalities through the IRP process. The requirement or encouragement of including DSM options in a utility resource plan, ratemaking reforms to remove disincentives to DSM adoption, as well as direct incentives for DSM adoption, and cost "adders" for various types of utility resources constitute the second type of PUC policy intervention.

Both types of policy intervention may be open to some criticism on both economic and public-interest grounds. The general criticism is that such intervention may distort prices and consumption choices, thereby causing inefficiencies that may override any potential benefits. This may be particularly true if PUC policies hinder competitive trends that are increasingly developing in the energy services industry. Other criticisms to PUC policy interventions to address externalities may be based on the competence, jurisdiction, and access to information resources of the PUC to effectively implement the intended policy objectives.

There are some legitimate reasons for PUC intervention to address externalities. Like other local public agencies, the PUC has a political mandate to advance local interests, even when its actions may be perceived to be in conflict with development of certain national interests, including development of interregional markets. Further, potential conflicts between states and the federal government generally need to be resolved under a broader political process that lies outside of the state commission regulatory process. Furthermore, the underlying rationale for any public intervention in markets, that of the failure of certain markets to produce and price goods at efficient levels, and the fact that the PUC is a public agency that can affect the production and the pricing of the energy service good, makes the PUC at least a plausible tool for any 
needed intervention. However, it can be argued that the limitations of competence, jurisdiction, and access to information resources narrow the role that the PUC should play in addressing externalities, particularly environmental externalities.

On such issues as the local economy, the rationale for PUC intervention mimics the "infant industry" argument that can be refuted by arguments generally advanced to refute protectionist policies. Furthermore, it can be argued that the state tax agency or the local development agency is better positioned than the PUC to carry out the wishes of the state legislature to attract and preserve jobs in the state.

Regarding environmental externalities, the role of the PUC is much more problematic. ${ }^{13}$ The PUC, designed to carry out economic regulation, is unlikely to have the expertise and access to information and other resources to develop and implement environmental policies. ${ }^{14}$ The federal or local environmental agency is much more capable of dispensing environmental policy than a PUC. Yet even the local environmental agency may be limited in dispensing environmental policy. Unlike local jobs and other local concerns, the ramifications of a state environmental policy have a greater significance for other states and regions; such ramifications can hardly be ignored. For example, the source of an environmental pollutant may be located and regulated in a certain state even though the pollution affects several states. In such a case, the costs of regulation are borne entirely by the residents of the state who receive only part of the benefits while no costs are borne by the residents of the other affected states. This outcome can be regarded as both inequitable and inefficient. Also, regulations of some sources of pollution without corresponding regulation for other

\footnotetext{
${ }^{13}$ For a detailed examination of the role of PUC regulation to address environmental externalities, see Kenneth Rose et al., Public Utility Commission Treatment of Environmental Externalities (Columbus, OH: The National Regulatory Research Institute, May 1994)

${ }^{14}$ Paul Joskow, "Weighing Environmental Externalities: Let's Do it Right!" The Electricity Journal 5, no. 4 (May 1992): 53-67.
} 
sources of pollution may inefficiently distort the use of fuels and other resources. ${ }^{\text {is }}$ If one can question the role of the local environmental agency in regulating pollutants with nonlocal effects, the role of the PUC, given its comparative disadvantage relative to the local environmental agency, is open to even more question. A sensible policy framework for a state to mediate environmental externalities would be to distinguish between pollution sources with local effects and nonlocal effects, and use the local environmental agency to effectively regulate the sources with local effects. For pollutant sources that affect multiple political jurisdictions, environmental policy should be pursued through federal initiatives, cooperative arrangements, and market solutions. In particular, PUCs may wish to coordinate their efforts with state and federal agencies to develop coherent environmental policies. ${ }^{16}$ In any case, the role of the state PUC should be minimal in addressing environmental externalities, whether of local or nonlocal scope.

The above discussion does not imply that the PUC should have no role in influencing the resource choices made by a utility under its jurisdiction to mediate externality effects. The discussion merely indicates the need for PUCs to closely examine their role in both addressing externality issues and ensuring that its policies are congruent with the objectives of other state agencies, the federal imperatives, and the working of markets (when they exist) in terms of relative competence, jurisdiction, and access to resources. This means that whenever the PUC wishes to pursue a broader social goal that goes beyond the PUC's primary mandate to ensure reliable and least-cost utility services, it may be best for the PUC to assume a facilitative rather than a directive role. For example, it is perfectly defensible for a PUC to promote cost-effective DSM options through a combination of incentive and procompetitive policies as long as the goal is to minimize the private resource costs to the utility and thereby minimize the

${ }^{15}$ The difficulty of addressing the broader ramifications of environmental policy may be characterized as the "piecemeal problem." For a discussion of the piecemeal problem, see NARUC, Environmental Externalities and Electric Regulation (Washington, D.C.: NARUC, September 1993), 35-44.

${ }^{16}$ For a detailed discussion of such options, see Rose et al., Public Utility Commission Treatment of Environmental Externalities. 
total private costs of energy services to the ratepayers (assuming that such policies also address equity issues). If successful, such policies may also facilitate environmental quality, although this may not have been an explicit objective of the PUC.

\section{IRP and the Market Failure Argument}

In discussions of IRP, two kinds of market failures are generally mentioned. One is the presence of externalities, which was discussed in the preceding section. The other is the inadequate development of the energy efficiency market. It is generally believed that had a well-functioning market developed for energy efficiency, the need for PUCs to promote utility-sponsored energy efficiency measures would virtually disappear. The absence of a well-functioning market for energy efficiency is believed to be one of the stronger arguments for PUC intervention in utility planning.

Several factors are cited as barriers to the development of the energy efficiency market. They include: the lack of customer access to information about DSM measures; the lack of credit and financial resources experienced by customers who could potentially acquire DSM resources; distorted customer perceptions about performance and pay-back periods of DSM measures; the high discount rate used by customers in evaluating the benefits of DSM measures; and the landlord-tenant relationship that tends to circumvent tenant choices for energy service options. ${ }^{17}$

It should be noted that the presence of barriers to the adoption of a certain product does not in itself indicate a market failure that requires public intervention. ${ }^{18}$ An efficient market may restrict entry of certain products because potential suppliers do not see sufficient profit opportunities to compensate for associated expenses and risks. The barriers faced by DSM measures are common to most innovative products. Yet, it

${ }^{17}$ Steve Wiel, "The Electric Utility as Investment Bank for Energy Efficiency," The Electricity Journal 4, no. 4 (May 1991): 30-39.

${ }^{18}$ For a theoretical review of the market failure problem, see Alan Randall, "The Problem of Market Failure." 
is not clear that the failure of every innovation to be deployed in the market constitutes a market failure.

In the case of DSM measures or energy efficiency products, there indeed may be a market failure. This failure is not so much due to the presence of barriers as to the potential undervaluation of the social benefits of DSM measures. If this is the case, there may be a persuasive argument for public intervention to promote the penetration of DSM measures. Such intervention may take the form of publicly funded dissemination of information, publicly funded research and development, government provision of low interest credit to investors, and tax benefits to investors. In the case of DSM measures, many of these actions have already been taken by various federal and state agencies. Specifically, the enactment of federally-mandated efficiency standards is intended to boost the market for DSM measures. ${ }^{19}$

It may be useful to discuss what role the PUC ought to play in addressing the potential market failure for energy efficiency products. Given the fact that there are other public intervention options available to stimulate the energy efficiency markets, it is reasonable to argue that the PUC should limit itself to those ameliorative actions that are compatible with its resources, competence, and mandate. Therefore, it may be appropriate for the PUC to encourage and sanction utility-sponsored credit and rebate programs to expedite the acceptance and penetration of DSM measures, as long as the main objective is to ensure the delivery of energy services at least cost and at acceptable reliability. As a matter of good public policy, PUCs should strive for an equitable sharing of such costs, based on cost responsibility, among ratepayers. Programs to disseminate information may merit across-the-board funding from all ratepayers. Clearly, the PUC can pursue incentive-based ratemaking policies to remove disincentives that inefficiently impede the adoption of energy efficiency options.

\footnotetext{
19 National standards were established by the National Appliance Energy Conservation Act of 1987 (NAECA) for various residential appliances and heating, ventilating, and air conditioning (HVAC) equipment. The standards were extended by the Energy Policy Act of 1992 (EPAct) to cover commercial HVAC equipment and water heaters.
} 
It should be recognized, however, that both government and PUC actions to stimulate energy efficiency markets should be temporary, only lasting as long as inefficient barriers to adoption persist. If for example, a point is reached when customers have reasonable access to information and financing regarding energy efficiency products, increasing or continuing with the existing level of information dissemination and financing may be wasteful and unproductive. If the remaining barriers consist of the persistence of high private discount rates or insufficient technological development, nothing would need to be done about the first group of barriers. Public efforts should instead concentrate on improving the pace of technological development.

The reason for the first conclusion is that if customers have sufficient information to choose discount rates for various investments and still persist in choosing discount rates far above what experts believe to be the appropriate social discount rate, then the experts must defer to the time-honored notions of individual responsibility and consumer sovereignty. The experts then must concede defeat to the recalcitrant customer and declare in exasperation, to quote Alfred Kahn, "to hell with them." ${ }^{20}$ The reason for the second conclusion is that insufficient technological development of products cannot always be addressed by markets, thereby warranting public support but only in proportion to expected benefits

Another issue is the apparent incompatibility of a firm selling two products that compete with each other. Selling energy and selling energy efficiency are inherently in conflict. How would a supplier of gasoline, for example, operate if it were cajoled, incentivized, or subsidized also to sell fuel-efficient cars? The results would, at best, be unpredictable and at worst, perverse with no assurance that the desired level of fuelefficiency would be achieved. IRP-based PUC initiatives to reduce or remove the sales bias of the energy utility company resemble this example. More appropriate alternatives

${ }^{20}$ Alfred Kahn, "An Economically Rational Approach to Least-Cost Planning," The Electricity Journal 4, no. 5 (June 1991): 11-20. 
to the above scenarios would be to support the development of the market for fuelefficient cars or energy-efficient appliances separately from the market for gasoline or energy. If, however, some creative regulatory arrangement happens to achieve an optimal mix of the energy product and the energy efficiency product, such arrangement needs to be considered a temporary ameliorative measure ultimately to be abandoned in favor of appropriate and separate markets.

Another, and somewhat optimistic, possibility is developing an integrated "energyservice" product, which can be appropriately packaged and priced. Yet even such an optimistic development may be better facilitated by markets rather than by economic regulation. This is a possibility that regulated utilities and other energy service providers may be advised to look into, in the interest of their own bottom lines, without regard to PUC entreaties and incentives. Either of the above outcomes, the development of a thriving energy efficiency market or the emergence of the integrated energy service product market, would please IRP proponents without raising any objections from IRP detractors. Incentive-based PUC initiatives can potentially provide a much needed, and short-lived, stepping stone toward either, or both, of these outcomes.

\section{An Examination of IRP Issues Specific to the LDC}

The foregoing discussion addresses issues arising from applying the IRP process to both electric and gas utilities. However, there are clear differences between the electric utility and the LDC that require further analysis to facilitate an understanding of the implications of the IRP process for the LDC.

\section{Differences between the Electric Utility and the LDC}

Electric utilities and LDCs differ in many respects including (1) industry structure, (2) planning horizons, (3) end-use characteristics, (4) relationship between the primary input resource and the output product, (5) input price stability, (6) access to retail utility services, (7) avoided supply side costs of DSM options, (8) fuel-switching options, and 
(9) environmental impacts of the production and consumption of the energy service. ${ }^{21}$ Each of these differences has significant implications that should be taken into account in developing PUC policies to facilitate IRP objectives. ${ }^{22}$

\section{Industry Structure and IRP}

The electric utility industry is comprised of vertically integrated utilities with responsibilities for procuring fuel, constructing facilities for energy generation, transmitting electricity across state and city lines, and delivering the electricity to the end user. The gas industry, as a result of the dynamic interplay of market forces and FERC initiatives, has evolved into a highly segmented structure with different segments responsible for production (wellhead producers), interstate transmission (pipelines), and LDCs. $^{23}$ Aithough some integration of these functions existed until recently, the latest FERC initiative, namely Order 636, intends to completely unbundle the gas supply services. ${ }^{24}$ Also, a market has developed for gas marketers and brokers who offer gas aggregation services to LDCs as well as to end users. Furthermore, end users can now directly buy gas from producers or marketers and receive distribution services from the LDC, indicating complete unbundling of gas supply services from "the wellhead to the burnertip."

21 National Association of Regulatory Utility Commissioners, Primer on Gas Integrated Resource Planning (Washington, D.C.: NARUC, December 1993), 15-21. See also, Michael E. Samsa and William F. Hederman, "Gas Utility Resource Planning: How Far Does the Electric Analogy Go?" Public Utilities Fortnightly (October 1, 1992): 40-42.

22 Ibid., "Gas Utility Resource Planning."

${ }^{23}$ Mohammad Harunuzzaman, Kenneth W. Costello, Daniel J. Duann, and SungBong Cho, Incentive Regulation for Local Gas Distribution Companies Under Changing Industry Structure (Columbus, OH: The National Regulatory Research Institute, December 1991).

${ }^{24}$ For a detailed discussion of the implications of Order 636, see Daniel J. Duann, The FERC Restructuring Rule: Implications for Commissions (Columbus, OH: The National Regulatory Research Institute, November 1993). 
Both restructuring of the gas industry and the unbundling of services have important implications for IRP. The segmented structure makes the LDC a price taker in an essentially unregulated market for the primary input, the gas commodity. However, getting the least-cost portfolio of supply sources through full exploitation of market opportunities depends on the skills and diligence of the LDC. In crafting regulatory policies, the PUC should ensure that incentives are provided for the efficient procurement of supply side resources. The same logic applies to the reliability of supply side resources. Previously, the pipeline provided contractual guarantees of supply reliability to the LDC. The new structure shifts this responsibility entirely to the LDC. Although, during the initial transition period, this may increase the supply reliability risk to the LDC, the risk may in fact be lower as the market matures and weeds out lowreliability suppliers. Both during the transition period and later in a fully developed market, ensuring adequate supply reliability would also depend on the skills and diligence of the LDC in finding reliable suppliers and negotiating efficient contracts. This requires the PUC to use incentives or oversight to promote reliability.

The foregoing discussion implies that regulatory policies should be avoided that either unduly constrain the flexibility of the LDC in its procurement choices or unduly shift the risks of such choices to ratepayers. A desirable policy would balance the LDC's flexibility in making procurement choices and the risks (both with respect to price and reliability) accompanying such choices. Close oversight or preapproval of procurement plans, by limiting the flexibility of the LDC and shifting the accompanying risks to ratepayers, may result in higher resource costs. Regulatory practices which ensure cost passthroughs (such as PGAs) would tend to have the same effect.

\section{Planning Horizons and IRP}

An LDC has typically a shorter planning horizon than an electric utility. Unlike the electric utility, the LDC has a relatively lower investment in facilities that require long construction times, massive expenditure of capital, and long economic lives. The typical planning horizon of an electric utility is about thirty years, which approximates 
the economic life of the utility's long-lived assets. The typical planning horizon of a gas utility is between one and ten years, ${ }^{25}$ which approximates the length of the LDC's supply and transportation contracts.

The relationship between the effective pay-back period of resource options and the planning horizon is an important consideration in resource planning. As an extreme example, if a home were to be weatherized with a pay-back period of ten years, the owner is unlikely to weatherize if she were planning to sell the house in five years. It is important to observe that the pay-back period of most conservation and DSM options is much lower than the typical planning horizon of the electric utility. The pay-back period is generally comparable or longer than the typical planning horizon of a gas utility. This implies that the resource planning analysis should be sensitive to the relationship between the pay-back period and the planning horizon.

\section{End-Use Characteristics}

One important difference between end-use retail customers in the electricity and gas industries lies in the ability of certain customers to access alternative sources of supply. Large industrial and commercial customers of the LDC generally have opportunities to switch to an alternate fuel, an alternative gas supplier, or bypass the LDC altogether by linking directly to a pipeline. Such alternatives are not yet available to the same degree for electricity customers.

The access to alternatives available to a large segment of retail gas customers has important implications for IRP. The availability of alternatives is likely to make such customers price sensitive. Any ratemaking policy that actually raises or is perceived to raise the price of gas to such customers relative to the price of an alternative is likely to cause the customer to either reduce the take of gas from the LDC or drop off the system altogether. Therefore, such a policy may have the effect of not collecting the expected

${ }^{25}$ NARUC, Primer on Gas Integrated Resource Planning, 15. 
revenues from retail customers with other options and who are nonparticipants in a DSM program. To make up the resulting loss of revenue, rates may have to be raised to remaining core customers. Finally, if there are price-sensitive core customers in the system, such customers may also reduce their gas purchases. The likelihood of such a scenario is open to empirical examination but merits consideration in setting customer rates.

The foregoing discussion indicates that to ensure an IRP will be effective, all resources must pass the total resource cost (TRC) test and should also score high on the RiM test. If the resource mix does not pass the RIM test in the short run, it should at least pass the test in the long run. Short-run rate impacts, however, should not be ignored in evaluating a resource plan.

The current rate-setting policies in most states may make the above discussion somewhat moot. Generally, an LDC recovers the cost of gas supplies on a dollar-bydollar basis. Fixed costs and carrying charges are usually recovered through transportation charges. Therefore, the revenue loss associated with lost gas sales does not represent a direct earnings loss to most LDCs. In other words, the "stranded investment problem" for LDCs is less severe than for the electric utility threatened with retail wheeling because the relevant investment, the distribution network, is still used mostly to provide a monopoly service with unchanged opportunities to recover carrying charges. Therefore, the LDC may not be as eager to retain sales customers as would be the case for an electric utility. For the same reason, the LDC may have less need to address the lost revenue problem due to cost-effective DSM programs. There may, however, be a "stranded contracts" problem as the planned portfolio of gas supply and transportation contracts become surplus if customers choose to significantly reduce their gas purchases. This may not be a significant problem if the LDC has options to resell its contracts, although the related transaction costs cannot be entirely ignored. The potential for lost revenues does exist, however, from both participants (because of decreased throughput resulting from reduced sales), and nonparticipants (if there is significant bypass of the LDC's transportation service) as a result of cost-effective DSM programs. 
Several important conclusions follow from the discussion in this section. First, to ensure that the LDC recovers its projected revenue requirements, it is desirable that the resource options associated with an IRP be evaluated by both the TRC and RIM tests. Second, resource options that raise the price of LDC gas relative to alternatives may cause bypass of either the sales or the distribution service of the LDC. Third, bypass of the sales service alone may not cause serious problems if the LDC has options to resell its sales and transportation contracts and chooses to use such options rather than raising rates to remaining customers. Fourth, the lost revenue problem associated with costeffective DSM programs is likely to be less serious for the LDC than for the electric utility.

\section{Volatility of Input Prices}

The price of gas is perceived to be much more volatile than other fuels used in the production of electricity. There are three possible sources of such volatility. There is volatility associated with significant fluctuation of the seasonal demand for gas. There is also volatility expected with the emergence of a very fluid market, dominated by the spot market. Finally, there is widespread expectation that the "gas bubble" that exists today is likely to evaporate in the future and will cause sharp rises in gas prices.

Price volatility has different implications from the utility and the ratepayer perspectives. The utility would favor some rate guarantee of rate recovery, such as through the PGA, that is essentially independent of the volatility of gas prices. From the ratepayer perspective, the PGA causes the price risk to be shifted almost entirely to the ratepayer (there may be some sharing of risk if PGAs are subject to subsequent prudence reviews). Also, the PGA can cause rate instability if gas prices fluctuate significantly. Further, PGAs weaken the incentive for an LDC to be efficient in its gas purchase decisions. Other regulatory mechanisms, such as preapproval of gas purchase plans, may have the same effect in addition to reducing the LDC's flexibility in making gas purchases. It can also be argued that PGAs may run counter to the IRP objective of promoting energy efficiency because the utility may be indifferent to not only the price 
but also the amount of gas purchased. PUCs may want to reexamine their PGA policies to explore better ways to ensure rate stability and an equitable sharing of the price risk, and to provide incentives for making efficient gas purchase decisions. ${ }^{26}$

\section{Avoided Costs}

A fundamental rationale for an IRP process is the potential for significant savings to be achieved by adopting an all-inclusive resource mix that includes cost-effective DSM options. Both the magnitude of the energy savings and the resulting avoided supply side costs are important considerations in developing a resource mix. Some recent studies observe that the potential for avoiding supply side costs by adopting cost-effective DSM options is much smaller for the gas industry than for the electricity industry. ${ }^{27}$ If this is true, the regulatory effort expended in initiating and implementing an IRP should necessarily also be much smaller. This implies that regulatory mechanisms adopted to facilitate IRP objectives should use a minimum of staff and analytical resources, and oversight procedures. This also means that the PUC should make extensive use of emerging market forces to facilitate efficient decisionmaking and minimize the regulatory effort of achieving IRP objectives.

\section{Fuel-Switching Options}

Some energy appliances are capable of using both gas and electricity. For example, heaters and air conditioners can use either gas or electricity. A related IRP

${ }^{26}$ For an analysis of possible reforms of the PGA, see Robert E. Burns et al., Current $P G A$ and FAC Practices: Implications for Ratemaking in Competitive Markets (Columbus, OH: The National Regulatory Research Institute, December 1991).

${ }^{27}$ NARUC, Primer on Gas Integrated Resource Planning, 20. See also, M. Lerner and L. Piessens, "Comparison of Integrated Resource Planning: Natural Gas vs. Electric Utilities," Proceedings: Fourth National NARUC-DOE Conference on Integrated Resource Planning (Washington, D.C.: NARUC, September 1992). 
issue is whether the PUC, which has jurisdiction over both gas and electric utilities, should encourage fuel switching to promote energy efficiency. This is one area where it can be argued that customer choice rather than PUC regulation should determine the choice of fuels. As long as customers have access to information to judge the relative merit of different fuels in serving their energy service needs, ratepayers of any utility should not be asked to subsidize the marketing of the utility's or a competitor's fuel under the rubric of IRP. Such efforts should be treated as strictly marketing and subjected to the standard treatment accorded to other marketing activities of a utility. Also, the use of adders in electric IRP regulation may favor the use of gas because of the superior environmental characteristics relative to, say, coal. While a desirable outcome on environmental quality grounds, this outcome can also be realized through one of the other public intervention instruments, such as pollution taxes or emissions trading.

\section{Environmental Impact}

It has been argued previously that the PUC, given its limited expertise, jurisdiction (not coterminous with geographical pathways of environmental impacts), and access to resources is not well-positioned to address environmental externalities. The argument concludes that the PUC, however, may more appropriately play a facilitating role in influencing socially efficient environmental choices. ${ }^{28}$ This argument becomes stronger for the regulated gas utility sector given the fact that gas conversion processes generate fewer pollutants (mainly $\mathrm{CO}_{2}$ ) at lower levels than the fuel conversion processes in the electricity sector. Therefore, the rationale for the PUC playing an active role in influencing environmental choices is much weaker for the gas energy sector than the electricity sector. It follows that the PUC can facilitate the intended environmental objectives by pursuing the more traditional regulatory objective of energy efficiency.

${ }^{28}$ The PUC role in addressing environmental externalities is discussed in more detail in this chapter under "IRP and Externalities." 


\section{CHAPTER 4}

\section{CONCLUSIONS AND RECOMMENDATIONS}

The preceding chapters examined major regulatory issues related to gas IRP. A number of observations emerged that can be used to develop a framework to guide PUC policies. The policy framework can assist in developing a set of criteria to evaluate specific regulatory options.

\section{Summary of Observations}

The observations that emerged from the discussions in preceding chapters can be grouped into four categories: (1) the rationale of IRP objectives, (2) the role of PUCs as public-intervention vehicles to pursue IRP objectives, (3) the presence of barriers to the achievement of IRP objectives, and (4) the transfer of IRP concepts and methods used in the electricity sector to the gas sector.

First, it was observed that IRP objectives, namely energy efficiency and environmental protection, are legitimate and defensible social objectives. In the context of utility regulation, these objectives translate into promoting the delivery of energy services at the lowest achievable private and social costs.

Second, it was observed that the PUC can play a facilitating role in promoting IRP objectives if it can achieve the goal of minimizing the private costs of supplying energy. Given its limited expertise and resources, a PUC may not be well-suited to address environmental externalities and other social costs; other public agencies may be better positioned to perform this task. Furthermore, given the high likelihood that the environmental impact and related social costs may be much lower for gas than for electricity, the case for limited PUC intervention to address environmental externalities is further strengthened. Finally, in promoting energy efficiency, the PUC may wish to favor procompetitive and incentive-based options (in that order) over more interventionist-type options. 
Third, it was observed that the private market for energy efficiency measures may be underdeveloped. Yet such underdevelopment does not necessarily indicate market failure. However, the PUC can facilitate the development of energy efficiency markets by pursuing certain policies that directly address the barrier associated with customer perceptions and acceptance of DSM measures, and access to financing and credit of potential participants. Facilitating the development of the energy efficiency market, however, should be done on a temporary basis and be sensitive to rate impacts on different classes of customers.

Finally, it was concluded that uncritical transfer of IRP concepts and methods from the electricity sector to the gas sector would be ill-conceived. The differences in industry structures, planning horizons, end-user characteristics, price volatility of input prices, avoided supply side costs of DSM options, environmental impacts, and other factors between the two energy sectors require revision of the concepts and approaches used traditionally in the electricity sector for application to the gas sector. The general conclusion reached was that, in facilitating IRP objectives, a stronger need exists for procompetitive, incentive-based policies in the gas sector. It was further concluded that the IRP process should focus more attention on the supply side of the LDC's operations. Finally, it was suggested that the RIM test may be a more appropriate and important criterion for IRP in the gas sector than in the electric sector.

\section{Developing a Policy Framework}

The above observations can guide the development of a policy framework. The framework can embody a set of recommended guidelines for the administrative process, planning evaluation criteria, and regulatory-options evaluation criteria. The framework can be used by PUCs both to evaluate existing regulatory policies and to develop new regulatory approaches. 


\section{Guidelines for IRP Administrative Options}

IRP for LDCs should minimize the frequency and complexity of administrative oversight procedures. IRP proceedings can continue to be used to provide a forum for preliminary screening of resource options and to allow intervenor input. PUCs may wish to explore options to curtail the length and scope of adversarial hearings at the planning stage of the IRP process. PUCs may also wish to avoid direct ex ante approval of resource options both to retain the LDC's flexibility in making procurement and DSM resource choices and to preserve incentives for prudent decisionmaking. However, to allow the LDC to be innovative in managing its purchase portfolio, price risk, and DSM programs, clear ex ante rules for subsequent evaluations of LDC decisions should be established to overcome the asymmetry of risks and rewards underlying traditional regulation. Subsequent prudence reviews should clearly follow these rules; there should also be less reliance on PUC discretion. Incentive-based regulatory mechanisms would lessen the need for extensive oversight proceedings either at the planning or prudencereview stage of the regulatory process. Such proceedings should be limited to screening out obvious flaws in the LDC's resource plan at the planning stage and detecting instances of gross mismanagement at the prudence-review stage.

\section{Criteria for Evaluating LDC Resource Plans}

Most of the traditional criteria for evaluating resource plans should be retained. These include clear documentation of data and analytical tools used in developing the resource plan, clear presentation of cost and performance objectives of the plan, all estimations and calculations related to forecasts, the supply side resource mix, the DSM resource mix, avoided supply side costs expected to be achieved by DSM options, rate and bill impacts of DSM options, cost/benefit tests used, and analysis of risks and uncertainties. In addition, the LDC should be required to indicate how it proposes to fully utilize the competitive gas wholesale market to minimize purchase costs and price risks, efficiently utilize capacity procurement/release and storage options to achieve 
reliability targets, and use pricing flexibility to retain sales and transportation customers in a way that minimizes harm to core customers.

\section{Criteria for Evaluating Regulatory Mechanisms}

The following criteria can be used to evaluate regulatory mechanisms: cost minimization, energy efficiency, rate/revenue impact, ease of implementation, effect on competitiveness, and gaming opportunities. It should be noted that these criteria are similar to those applied in other studies. ${ }^{1}$ The proposed set of criteria emphasizes both energy efficiency and competitiveness, rather than the traditional IRP approach of emphasizing energy efficiency.

\section{Evaluation of Regulatory Mechanisms for IRP}

Based on the above criteria, a number of regulatory mechanisms are evaluated. The mechanisms evaluated include direct recovery of DSM costs, LRAs, RDMs, shared savings mechanisms, bonus ROR mechanisms, deregulation of the noncore market, and price caps. The summary evaluations are shown in Table 4-1.

\section{Traditional DSM Cost Recovery Mechanisms}

\section{Direct Recovery of DSM Costs}

Direct recovery of DSM costs can take two forms, expensing or ratebasing. Both options remove a significant disincentive to DSM adoption, namely, uncertainty about recovery of DSM program costs. Neither mechanism provides any clear incentive for

1 For example, see NARUC, Michigan Regulatory Incentives Study for Electric Utilities (Washington, D.C.: NARUC, June 1991). 
TABR 4-1

COMPARSON OP ALTERATVE RBCULATORY MBCHANSTS

\begin{tabular}{|c|c|c|c|c|c|c|}
\hline $\begin{array}{l}\text { Ratemaking } \\
\text { Mectuanism }\end{array}$ & $\begin{array}{c}\text { Cost } \\
\text { Minimization }\end{array}$ & $\begin{array}{l}\text { Energy } \\
\text { Efficiency }\end{array}$ & $\begin{array}{l}\text { Rate/Revenue } \\
\text { Impact }\end{array}$ & $\begin{array}{l}\text { Esse of } \\
\text { Implementation }\end{array}$ & $\begin{array}{c}\text { Effect on } \\
\text { Competitiveness }\end{array}$ & $\begin{array}{l}\text { Gaming } \\
\text { Potential }\end{array}$ \\
\hline $\begin{array}{l}\text { Expensing DSM } \\
\text { with Balancing } \\
\text { Accounts }\end{array}$ & $\begin{array}{l}\text { Negative. LDC gains } \\
\text { nothing by } \\
\text { minimizing costs. }\end{array}$ & $\begin{array}{l}\text { Mixed. Encourages DSM. No } \\
\text { incentive for reducing sales. }\end{array}$ & $\begin{array}{l}\text { May cause significant } \\
\text { rate increases. }\end{array}$ & $\begin{array}{l}\text { No significant } \\
\text { difficulties. }\end{array}$ & $\begin{array}{l}\text { May cause bypass } \\
\text { by price-etestic } \\
\text { customers. }\end{array}$ & Not significant. \\
\hline $\begin{array}{l}\text { Ratebasing DSM } \\
\text { Expenses }\end{array}$ & $\begin{array}{l}\text { Negative. LDC } \\
\text { gains nothing by } \\
\text { minimizing costs. }\end{array}$ & $\begin{array}{l}\text { Mixed. Encourages DSM. No } \\
\text { incentive for reducing sales. }\end{array}$ & $\begin{array}{l}\text { Semoothing of rate } \\
\text { impact. Long-term } \\
\text { revenues may be } \\
\text { higher. }\end{array}$ & $\begin{array}{l}\text { No significant } \\
\text { difficulties. } \\
\text { lncreased } \\
\text { sccounting } \\
\text { requirements. }\end{array}$ & Not clear. & $\begin{array}{l}\text { May huve a "gold- } \\
\text { platings } \\
\text { effect. }\end{array}$ \\
\hline $\begin{array}{l}\text { Lost Revenue } \\
\text { Adjustment }\end{array}$ & $\begin{array}{l}\text { Positive. LDC gains } \\
\text { by minimizing } \\
\text { DSM costs. No } \\
\text { effect on supply side } \\
\text { cost minimization. }\end{array}$ & $\begin{array}{l}\text { Mixed. Encourages DSM. Weak } \\
\text { incentive for reducing sales. }\end{array}$ & $\begin{array}{l}\text { May cause rate } \\
\text { increases. }\end{array}$ & $\begin{array}{l}\text { Requires } \\
\text { complex } \\
\text { estimation. } \\
\text { Potential for } \\
\text { court challenges. }\end{array}$ & $\begin{array}{l}\text { May cause bypass } \\
\text { by price-elastic } \\
\text { customers. }\end{array}$ & $\begin{array}{l}\text { Potential for } \\
\text { inflating } \\
\text { lost reveaue } \\
\text { extimates }\end{array}$ \\
\hline $\begin{array}{l}\text { Decoupling by } \\
\text { ERAM }\end{array}$ & $\begin{array}{l}\text { Positive. LDC gains } \\
\text { by minimizing } \\
\text { DSM costs. No } \\
\text { effect on } \\
\text { supply side cost } \\
\text { minimization. }\end{array}$ & $\begin{array}{l}\text { Positive. Encourages DSM. } \\
\text { Removes sales bias. }\end{array}$ & $\begin{array}{l}\text { May cause rate } \\
\text { increases. }\end{array}$ & $\begin{array}{l}\text { No significant } \\
\text { difficulties. }\end{array}$ & $\begin{array}{l}\text { May cause bypass } \\
\text { by price-elastic } \\
\text { customers. }\end{array}$ & $\begin{array}{l}\text { Potential for } \\
\text { infiating } \\
\text { revenue estimates. }\end{array}$ \\
\hline $\begin{array}{l}\text { Decoupling by } \\
\text { RPE }\end{array}$ & $\begin{array}{l}\text { Positive. LDC gains } \\
\text { by minimizing base } \\
\text { costs. No effect on } \\
\text { supply side cost } \\
\text { minimization. }\end{array}$ & $\begin{array}{l}\text { Positive. Encourages DSM. } \\
\text { Removes sales bias. }\end{array}$ & $\begin{array}{l}\text { May cause rate } \\
\text { increases. }\end{array}$ & $\begin{array}{l}\text { No significant } \\
\text { difficulties. }\end{array}$ & $\begin{array}{l}\text { May cause bypass } \\
\text { by price-elastic } \\
\text { customers. }\end{array}$ & $\begin{array}{l}\text { Potential for } \\
\text { manipulating } \\
\text { customer count. }\end{array}$ \\
\hline $\begin{array}{l}\text { Sharing of DSM } \\
\text { Savings }\end{array}$ & $\begin{array}{l}\text { Positive. LDC gains } \\
\text { by minimizing base } \\
\text { costs. No effect on } \\
\text { supply side cost } \\
\text { minimization. }\end{array}$ & $\begin{array}{l}\text { Positive. Encourages DSM. } \\
\text { Removes sales bies. LDC gains by } \\
\text { maximizing energy sevings. }\end{array}$ & $\begin{array}{l}\text { May cause rate } \\
\text { increases. }\end{array}$ & $\begin{array}{l}\text { High estimation } \\
\text { and verification } \\
\text { requirements. }\end{array}$ & $\begin{array}{l}\text { May cause bypass } \\
\text { by price-elastic } \\
\text { customers. }\end{array}$ & $\begin{array}{l}\text { Potential for } \\
\text { inflating energy } \\
\text { demand forecast. }\end{array}$ \\
\hline
\end{tabular}




\begin{tabular}{|c|c|c|c|c|c|c|}
\hline $\begin{array}{l}\text { Ratemaking } \\
\text { Mechanism }\end{array}$ & $\begin{array}{c}\text { Cost } \\
\text { Minimization }\end{array}$ & $\begin{array}{l}\text { Energy } \\
\text { Efficiency }\end{array}$ & $\begin{array}{l}\text { Rate/Revenue } \\
\text { Impect }\end{array}$ & $\begin{array}{l}\text { Ease of } \\
\text { Implementation }\end{array}$ & $\begin{array}{c}\text { Effoct on } \\
\text { Competitiveness }\end{array}$ & $\begin{array}{l}\text { Gaming } \\
\text { Potential }\end{array}$ \\
\hline $\begin{array}{l}\text { Bonus ROR for } \\
\text { DSM } \\
\text { Performance }\end{array}$ & $\begin{array}{l}\text { Effect on cost } \\
\text { minimization not } \\
\text { clear. }\end{array}$ & $\begin{array}{l}\text { Positive. Encournges DSM. } \\
\text { Removes sales biass LDC gains by } \\
\text { maximizing energy saving. }\end{array}$ & $\begin{array}{l}\text { May cause rate } \\
\text { increaser. }\end{array}$ & $\begin{array}{l}\text { High estimation } \\
\text { and verification } \\
\text { requirements. }\end{array}$ & $\begin{array}{l}\text { May cause bypass } \\
\text { by price-elastic } \\
\text { customers. }\end{array}$ & $\begin{array}{l}\text { Potential for } \\
\text { inflating cnergy } \\
\text { demand forecest } \\
\text { and a "gold- } \\
\text { plating" effect. }\end{array}$ \\
\hline $\begin{array}{l}\text { The Cicchetti } \\
\text { Proposal }\end{array}$ & $\begin{array}{l}\text { Positive. LDC gains } \\
\text { by minimizing costs. }\end{array}$ & $\begin{array}{l}\text { Positive. May be weak in } \\
\text { addressing the sales bias. }\end{array}$ & $\begin{array}{l}\text { May increase rates } \\
\text { but reduce bills to } \\
\text { participants. }\end{array}$ & $\begin{array}{l}\text { High estimation } \\
\text { and verification } \\
\text { requirements. }\end{array}$ & Not clear. & None identified. \\
\hline $\begin{array}{l}\text { Deregulate the } \\
\text { DSM Service }\end{array}$ & $\begin{array}{l}\text { Positive. } \mathrm{LDC} \text { gains } \\
\text { by minimizing costs. }\end{array}$ & $\begin{array}{l}\text { Not clear. LDC may forego DSM } \\
\text { services altogether. }\end{array}$ & $\begin{array}{l}\text { DSM service prices } \\
\text { separated from energy } \\
\text { rates. }\end{array}$ & $\begin{array}{l}\text { May imvolve } \\
\text { some transition } \\
\text { costs. }\end{array}$ & $\begin{array}{l}\text { Positive. } \\
\text { Nonparticipants } \\
\text { unaffected by } \\
\text { DSM. } \\
\end{array}$ & $\begin{array}{l}\text { Potential for } \\
\text { subsidization of } \\
\text { deregulated } \\
\text { service. }\end{array}$ \\
\hline Price Caps & $\begin{array}{l}\text { Positive. LDC gains } \\
\text { by minimizing costs }\end{array}$ & $\begin{array}{l}\text { Not clear. Does not address the } \\
\text { sales bias. }\end{array}$ & Stabilizes rates. & $\begin{array}{l}\text { Contentious } \\
\text { hearings on } \\
\text { setting price cap } \\
\text { parameters. }\end{array}$ & Positive. & $\begin{array}{l}\text { LDC may attempt } \\
\text { to raise the cap } \\
\text { and depress the } \\
\text { productivity index. }\end{array}$ \\
\hline $\begin{array}{l}\text { Deregulate the } \\
\text { Noncore Market }\end{array}$ & $\begin{array}{l}\text { Positive. LDC gains } \\
\text { by minimizing costs. }\end{array}$ & $\begin{array}{l}\text { Not clear. Does not address the } \\
\text { sales bias. }\end{array}$ & $\begin{array}{l}\text { Regulated rates not } \\
\text { affected. }\end{array}$ & $\begin{array}{l}\text { May imolve } \\
\text { transition costs. }\end{array}$ & Positive. & $\begin{array}{l}\text { Porential for self- } \\
\text { dealing abuse. }\end{array}$ \\
\hline
\end{tabular}

Source: Authors' construct. 
minimizing DSM costs, compensates the utility for lost sales, or otherwise reduces the sales bias. Therefore, neither mechanism clearly promotes either cost minimization or energy efficiency. In addition, expensing can have significant rate effects, including the potential of raising ratcs. This can cause nonparticipating customers with fuel or supplier alternatives to bypass either the sales or the transportation service of the LDC. The rate impact of ratebasing is much weaker because of amortization. However, the ratebasing treatment may induce a "gold-plating effect" traditionally associated with supply side investments.

\section{Lost Revenue Adjustment (LRA) Mechanisms}

LRA mechanisms compensate the utility for sales lost to DSM by removing a disincentive for engaging in DSM. LRA mechanisms do not provide any incentives for minimizing DSM costs and do not completely remove the sales bias. Therefore, LRA mechanisms do not contribute to cost minimization; they also provide weak incentives for energy efficiency. LRA mechanisms by causing rate increases would tend to enhance the possibility of bypass. LRA mechanisms can also induce utilities to inflate estimates of lost revenues.

\section{Revenue Decoupling Mechanisms (RDMs)}

By severing the link between sales and revenues, RDMs remove a significant disincentive to DSM adoption. RDMs can take the form of fixed revenue caps that are adjusted each rate period either by projected revenue requirements (the ERAM mechanism) or by revenue per customer (the RPC mechanism). RDMs provide incentives to minimize DSM costs since profits depend on the difference between revenues, which are fixed, and costs, which the utility can control. RDMs remove the sales bias and clearly promote energy efficiency. RDMs, however, can raise rates and cause bypass. Also, the utility may attempt to maximize revenues through an RDM by either making inflated revenue requirement forecasts or manipulating the customer count. Among the two RDM mechanisms, RPC is superior in assuring cost-effective performance because customer growth is not directly amenable to utility control. 


\section{Performance-Based Mechanisms}

Shared savings and bonus ROR constitute two of the important performancebased incentive mechanisms. Both may induce the utility to minimize costs during the implementation stage of a DSM program. Both mechanisms may encourage energy efficiency as the utility earnings increase with increased energy savings. Both mechanisms may increase rates and cause bypass. Both mechanisms may induce the utility to overstate energy demand. In addition, the bonus ROR mechanism may induce "gold-plating" of DSM investments.

\section{Innovative DSM and Supply Side Cost Recovery Mechanisms}

\section{The Cicchetti Proposal ${ }^{2}$}

Cicchetti and Moran proposed a novel concept for promoting energy efficiency that essentially eliminates the cross-subsidy feature of the traditional IRP cost recovery mechanism. The proposal makes a clear use of the "energy service" concept germane to the IRP approach. In this respect, this proposal is a clear departure from other IRP regulatory mechanisms that use the energy service concept in estimating resource costs but abandon the concept when dealing with cost responsibility.

According to the Cicchetti proposal, a customer would be charged for energy services, which include both the energy commodity consumed and the amount of energy saved. In other words, a customer would pay for therms of gas consumed and therms

2 Charles J. Cicchetti and Ellen K. Moran, "Utility Energy Services," Regulatory Incentives for Demand-Side Management, Steven M. Nadel, Michael W. Reid, and David R. Wolcott, eds. (Washington, D.C.: American Council for an Energy-Efficient Economy, 1992), 163-86. 
saved attributable to conservation measures. The charge for energy saved would appear as a charge on the customer's regular bill.

The Cicchetti proposal provides incentives for cost minimization. Since the customer is charged a fixed price for energy services based on estimated savings, the utility gains by minimizing installation and operating costs of the conservation measure. The proposed mechanism also addresses the sales bias by compensating the utility equally for both the energy commodity sales and conservation savings. One positive feature of the proposed mechanism is the absence of cross subsidies: only the beneficiaries of conservation are charged for this service. Therefore, since the mechanism imposes no inequitable rate increases on nonparticipants, the competitive position of the utility is not compromised. Implementing the proposal, would, however, require accurate estimation and verification of energy savings.

\section{Provide DSM as a Separate Deregulated Service}

PUCs may wish to consider allowing an LDC to form a separate unregulated subsidiary to provide DSM services. This would subject DSM to a true market test responsive to customer preferences. Obviously, such an arrangement would induce the utility subsidiary to minimize its DSM costs. It is not clear whether energy efficiency would be promoted to the degree induced by one of the traditional regulatory mechanisms. Market risk may discourage the utility from using this option. Finally, the issues of implementation and competitiveness in the commodity market become somewhat moot since the service in question is no longer regulated. Self-dealing abuse may occur if the utility is allowed to make payments to the DSM subsidiary or engage in any kind of service coordination.

\section{Supply Side Incentive Mechanisms}

None of the above mechanisms addresses cost minimization on the supply side. However, providing incentives to the utility to minimize supply side costs may be cruciai 
as the new competitive environment presents both vastly expanded procurement opportunities and increased price and supply reliability risks to the LDC. PUCs may wish to ensure that the ratepayers are getting their gas at the lowest price for a given level of reliability.

Supply side incentive mechanisms that merit consideration include cost-indexing or cost-sharing schemes, price caps, and deregulation of the noncore market. ${ }^{3}$ All of these schemes are characterized by increased reliance on market forces. Cost-indexing schemes allow a sharing of costs below a bench mark that may be based on a utility forecast, a utility yardstick, the spot price, or the futures price of gas. Price caps, which have been used in the telecommunications industry, would set a cap on retail gas prices that can be periodically adjusted on the basis of an inflation index and a productivity offset. Finally, deregulation of the noncore market allows the utility complete flexibility of pricing gas to the fuel-switchable and price-elastic retail end-user market.

Each of the supply side regulatory incentives can achieve cost minimization of resource acquisition choices. However, they do not provide any direct incentives for energy efficiency. The rate impacts of such incentive mechanisms have some potential for bypass or price discrimination. For example, a price cap that applies to a basket of services but allows price flexibility among customers may cause price discrimination. As another example, deregulation of the noncore market may allow the utility to subsidize the noncore market with revenues from the core customers. These problems can be remedied, however, by limiting the price cap to core customers in the first case and providing protection against self-dealing abuses in the second case.

${ }^{3}$ Supply side incentive mechanisms are not examined in detail in this report. For descriptions of these and other supply side incentive mechanisms, see Mohammad Harunuzzaman et al., Incentive Regulation for Local Gas Distribution Companies Under Changing Industry Structure (Columbus, OH: The National Regulatory Research Institute, December 1991). 


\section{Developing Regulatory Approaches to Pursue IRP in the New Competitive Environment: Some Recommendations}

Given the new competitive environment that continues to develop in the gas industry, LDCs need flexibility in efficiently exploiting the expanded opportunities for acquiring gas supplies and competing aggressively for end-use markets. The new realities warrant a new approach to regulating LDCs. The IRP approach to regulation, which arguably served the energy industry well during the last decade by introducing a higher level of accountability, and promoting energy efficiency and environmental protection goals, should be refashioned to better fit the realities of the competitive gas industry. The emphasis should shift from scrutiny, oversight, and complicated verification procedures and compliance rules to greater reliance on market forces and customer choice. The onus for overcoming the barriers to energy efficiency should largely shift to other, less distortive, instruments of public intervention such as pollution taxes, subsidies for research and development, raising appliance standards, and again to market-based remedies such as trading of pollution rights ( $\mathrm{CO}_{2}$ trading in the case of gas). PUCs can, however, continue to play a facilitative, rather than interventionist, role in promoting IRP objectives.

PUCs have several choices that would facilitate IRP objectives and yet allow the LDC to assume a competitive posture in the new environment. To promote energy efficiency, a PUC can choose any combination of regulatory procedures and ratemaking mechanisms that satisfy a number of principles.

Specifically, regulatory procedures should rely more on ex ante setting of rules rather than ex post determinations of prudence. Some minimal level of ex post prudence reviews should be retained to detect obvious instances of mismanagement. The PUC should establish a clear set of rules $e x$ ante by which utility actions will be judged later; blanket preapproval of a plan or specific expenditures should, however, be avoided. This is necessary to allow greater decisionmaking flexibility to the utility, retain a certain degree of utility accountability for its actions, and prevent an undue shifting of risks to ratepayers. 
Among the ratemaking mechanisms promoting energy efficiency, PUCs may wish to favor those that both remove disincentives to engaging in DSM and encourage cost minimization. In addition, the rate-setting procedure can be designed independently of revenue recovery procedures with greater emphasis placed on cost responsibility. Otherwise, the IRP process will not only be inequitable but perhaps unsustainable if a large number of nonparticipants have access to alternative fuels, gas suppliers, or transportation providers. Finally, ratemaking mechanisms should attempt to minimize the need for complicated verification procedures given the uncertainty and controversy that surround such procedures. Among the various traditional and nontraditional ratemaking mechanisms, revenue decoupling mechanisms, the Cicchetti proposal, and deregulation of DSM services merit consideration by PUCs. Each of these mechanisms satisfy most of the criteria set above; each PUC, however, should carefully examine each mechanism in the light of its own needs and capabilities, and ability to address potential pitfalls (see Table 4-1).

When choosing among regulatory procedures and ratemaking mechanisms to promote supply side cost minimization, criteria similar to those discussed in the preceding section should be applied.

PUCs should rely more on clear ex ante rules (but not preapproval) and less on ex post determinations of prudence. The rules should include clear guidelines by which LDC procurement decisions will be judged. The use of PUC discretion in ex post prudence reviews should be minimized: prudence reviews should be limited to the detection of obvious cases of mismanagement.

Among the ratemaking mechanisms, greater reliance should be placed on market forces. Such an approach requires expanding both the decisionmaking flexibility and risk exposure of the LDC. This would allow the LDC to be an aggressive purchaser in the highly competitive gas supply market and an aggressive seller in the end-use market. PUCs may wish to consider price caps, deregulating the noncore market, and other nontraditional regulatory options. In particular, PUCs may wish to consider either eliminating or substantially reforming the PGA to encourage least-cost gas purchasing.

Finally, PUCs should achieve some congruence between regulatory options designed to achieve end-use efficiency and regulatory options designed to promote supply side cost minimization. For example, deregulating DSM service introduces no conflict 
with deregulating the noncore market. But an RDM regime may not conform well to a price-cap arrangement. On the other hand, an RDM mechanism can probably work well with a reformed PGA rule. Importantly, a PUC should craft the right combination of regulatory mechanisms that mesh well and are responsive to the state commission's own particular needs. 



\section{INTEGRATED RESOURCE PLANNING FOR LOCAL GAS DISTRIBUTION COMPANIES: \\ A CRITICAL REVIEW OF REGULATORY POLICY ISSUES}

\section{Dear Reader:}

As a part of our ongoing effort to assess the usefulness of our studies and reports to the regulatory community, we have included this evaluation for your possible use.

Please complete and mail to: NRRI, 1080 Carmack Road, Columbus, Ohio, 43210.

1. Was the information contained in the report clearly presented and in useful format?

2. If the report was helpful to you in your regulatory work, please check the appropriate statement(s).

- Report provided additional background information.

- Report provided a new technique for addressing a regulatory issue or problem.

- Report was useful in a regulatory proceeding or in preparing material for such a proceeding.

3. Additional comments about report.

4. Please list particular issues or areas for future research by NRRI which you would find useful.

5. Did you send for this report?

6. Respondent information (optional):

Name:

Position:

Organization/Affiliation: 

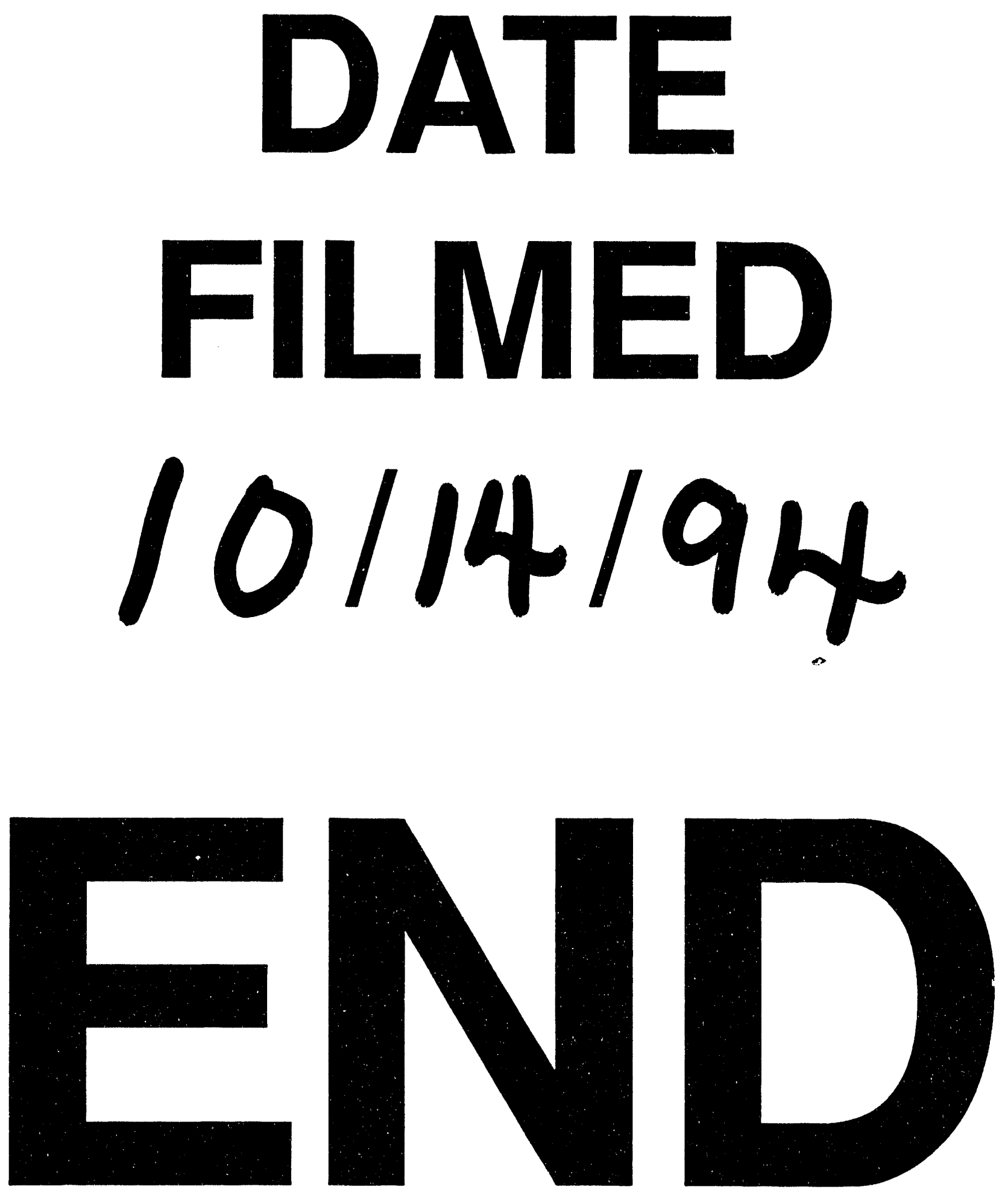
